\title{
Géolinguistique
}

21 | 2021

Varia

\section{De quelques problématiques liées à la phytonymie} occitane

Some Issues Related to Plant Name Occitane

Josiane Ubaud

\section{(2) OpenEdition}

Journals

Édition électronique

URL : https://journals.openedition.org/geolinguistique/5977

DOI : 10.4000/geolinguistique.5977

ISSN : 2650-8176

Éditeur

UGA Éditions/Université Grenoble Alpes

Édition imprimée

ISBN : 978-2-37747-303-8

ISSN : 0761-9081

Référence électronique

Josiane Ubaud, « De quelques problématiques liées à la phytonymie occitane », Géolinguistique [En ligne], 21 | 2021, mis en ligne le 06 décembre 2021, consulté le 19 décembre 2021. URL : http://

journals.openedition.org/geolinguistique/5977 ; DOI : https://doi.org/10.4000/geolinguistique.5977

Ce document a été généré automatiquement le 19 décembre 2021.

Géolinguistique 


\section{De quelques problématiques liées à la phytonymie occitane}

Some Issues Related to Plant Name Occitane

Josiane Ubaud

\section{NOTE DE L'ÉDITEUR}

Nous restituons les noms occitans en caractères gras. Mais la langue occitane connaît plusieurs graphies : la graphie historique dite classique (celle en usage majoritaire actuellement, notamment dans les universités), diverses graphies phonétiques dites patoisantes en référence au français (antérieures à 1850), et une amélioration de celles-ci dite graphie mistralienne (surtout utilisée en Provence), mais toujours en référence au français. Si nous écrivons nos articles toujours en graphie classique, par contre nous restituons la graphie de l'auteur que nous citons : ex. rore, nom du chêne blanc, rosèla, nom du coquelicot, s'écrivent roure, rousello en graphie mistralienne. Donc rosèla et rousello ne sont pas deux noms différents du coquelicot (comme on peut le voir dans certains ouvrages de compilation), mais le même vocable écrit dans deux graphies différentes, la première classique, la deuxième phonétique à la française. Précisons que nous appliquons les règles orthographiques du Conselh de la Lenga Occitana, que restitue notre Diccionari Ortografic (2011).

\section{Les sources et leur fiabilité relative}

\subsection{Les dictionnaires généraux}

1 Comment s'assurer de la fiabilité des sources écrites ? C'est un problème majeur auquel nous nous heurtons sans cesse. Les grands dictionnaires généraux de la langue d'oc (par exemple Boissier de Sauvages, 1756, augmenté en 1820 ; Honnorat, 1845 ; Vayssier, 1879 ; Mistral, 1880) restituent quantité de noms, mais pas toujours localisés avec 
précision. Si l'on peut en localiser certains par une caractéristique dialectale, la majorité pourrait être relative à plusieurs dialectes, morphologiquement parlant. Mais il était impensable qu'un auteur de dictionnaire, bénévole, sans aucun moyen que sa ténacité à vider un puits sans fond, puisse restituer un tel degré de précision géographique. Aimé Vayssier (1879) dans son Dictionnaire patois-français du département de l'Aveyron précise parfois le village :

- «Jórro, espèce de joncs qui vient dans les prés gras ou humides, Saint-Sernin » (p. 338) ;

- « Fustet, troène, Peyreleau » (p. 286);

- «Gamás, cépée, rejetons qui viennent sur le chicot d'un arbre, Camarès » (p. 287).

Est-ce à dire que ces noms sont limités à ces villages? Non, bien sûr. Il en est de même pour l'entrée «Hermes, Terre inculte » où Vayssier précise que c'est pour Millau : or, le terme est largement languedocien et confirmé par d'innombrables toponymes. Par contre, lorsque Mistral précise : «erbo-de-sant-Brancaci, n. f. Polypode du chêne, herbe qui croît en abondance près de l'église de Saint-Pancrace à Digne »; « erbo-de-sant-Canis, n. f. Lauréole, plante qu'on trouve abondamment à Saint-Quinis près Toulon ", il est évident que ces noms formés sur des microtoponymes ne peuvent être utilisés ailleurs. Cela n'empêche point des compilateurs postérieurs de les proposer comme noms génériques du polypode ou de la lauréole, par exemple dans un dictionnaire prétendant de plus restituer exclusivement le provençal parlé «dans l'intimité des familles rhodaniennes " (Coupier, 1995). Lequel dictionnaire contient bien d'autres erreurs que nous avions analysées dans un article détaillé publié sur notre site (Ubaud, 2017:5), dont nous ne citons qu'une partie concernant un point botanique :

Par exemple dans le dictionnaire de J. Coupier, il est donné comme traduction générale de plantain, plantage, èrbo de cinq còsto. Or èrba de cinc còstas ne saurait convenir comme traduction générale, tous les plantains n'ayant certes pas cinq nervures (voir tous les Plantago cynops, psyllium, arenaria, subulata, maritima, aux fines feuilles en alène, ou le plantain corne-de-cerf parfaitement identifié populairement). Suivent quelques noms d'espèces spécifiques, mais curieusement pas le plantain lancéolé, le plus répandu de tous, dont le nom est justement èrba de cinc còstas.

On verra ci-dessous que « le plantain » est décidemment sujet à bien des maltraitances linguistiques.

3 Il convient aussi d'attirer l'attention sur la polysémie d'une entrée chez F. Mistral (1879-1886 : 158). Lorsqu'à l'entrée jauneto nous trouvons les traductions «Trigonelle corniculée, chlore perfoliée, lotier corniculé, lichen des arbres fruitiers", le vocable a peu de chances de concerner tout le domaine occitan, encore moins toutes ces plantes sur un même domaine. Il en est de même pour «coucudo, primevère, plante à fleurs jaune, en Auvergne ; branc-ursine en Velay ; narcisse jaune, en Rouergue ». Ici encore, les localisations sont informatives et non pas restrictives (nous avons relevé en Cévennes gardoises cocuda pour Narcissus pseudonarcissus).

4 Enfin, encore plus inextricables sont les entrées avec variantes dialectales et concernant plusieurs plantes possibles. Se pose alors la question : quelle plante parmi celles énumérées correspond à quelle variante dialectale ? Seul un dépouillement précis par dialectes pourrait établir les correspondances exactes nom/plante. Ce sont pourtant les erreurs récurrentes que commettent à nouveau les copieurs faisant systématiquement les correspondances entre toutes les plantes indiquées et toutes les formes dialectales de l'entrée de base. Nombreux sont les exemples illustrant ces diverses imprécisions dans le dictionnaire de F. Mistral et générant des erreurs en 
cascade chez ses compilateurs, car souvent peu ou pas compétents ni en botanique ni en dialectologie :

- «Pèd-de-poulin, ped-de-pouli (rouerg.), pèd-pouli, pepouliéu (l.): pas-d'âne, tussilage, en Velay. » (p. 515)

On note la contradiction entre les localisations rouergate et languedocienne des entrées, et le Velay de la traduction.

- «Blavet, blauet (1.), baluet (g.) : bleuet [...] ; aphyllante. » (p. 299)

La traduction d'aphyllanthe ne saurait être du gascon, plante absente de ce territoire, et sans doute pas sur tout le domaine où cette plante est présente.

- «Argelas, argierac, argilac (niç.), argelat (carc.), arjalat (narb.), argielas, arjalas, ourjalas (1.), argieras, argeiras, argeirau (m.), arjalla (for.), argelègre (carp.) : genêt épineux; ajonc de Provence. » (p. 128)

Pour chaque variante dialectale donnée, quelle est la plante qui correspond ? Sachant qu'elles ne se trouvent pas toutes les deux sur tous les territoires donnés, voire pas du tout (en Forez par exemple). Encore manque-t-il Calycotome spinosa et sans doute Ulex europaeus (ce dernier pourrait concerner la forme forézienne), toutes ces plantes épineuses ayant en effet une même racine pré-indo-européenne arg- signifiant épine.

- «Embriago, ebriago, ubriago (m.), ubriajo (a.), embriaigo, embrèigo (1.), abirago, birago, virago, irago (g.), bidago (rouerg.), avirajo, virajo, ivirage (lim.) : ivraie, lotier corniculé, gesse à larges feuilles, inule visqueuse, doronic, valériane rouge, colchique d'automne, narcisse à bouquet, corroyère, fumeterre, plantes ainsi nommées à cause des propriétés enivrantes qu'on leur attribue ou à cause de leurs fleurs couleur de vin. » (p. 870)

Même remarque que précédemment: à quelle(s) plante(s) correspond tel nom dialectal ? Il est parfaitement impossible de répondre d'après ces données.

\subsection{Les lexiques spécialisés}

Les lexiques plus localisés (soit géographiquement, soit thématiquement) demandent une enquête plus fine pour déterminer la fiabilité de l'auteur. Lorsque celui-ci décrit sa méthode, les gens qu'il a rencontrés, et qu'en plus il précise le village ou le canton pour chaque nom relevé, on est vraiment en présence d'un document fiable, donc exploitable dialectalement : ces cas sont très rares. Dès le début du XIX ${ }^{e}$ siècle en effet, on se heurte au syndrome de la compilation. On a ainsi à profusion des «Catalogue des plantes vasculaires de (nom d'une ville) » dont on ne tarde pas à s'apercevoir qu'il résulte de la compilation d'autres «Catalogue des plantes vasculaires de (nom d'une autre ville à $100 \mathrm{~km}$ voire plus)", lui-même issu d'autres compilations, mais jamais citées. La volonté louable de donner les noms occitans se dispense de méthode scientifique sur le plan dialectal.

6 De plus, les auteurs de ces catalogues n'étaient pas ou peu occitanophones, mais botanistes, et restituent donc les noms avec la plus grande approximation phonétique en référence au français. Une èrba de lapaç (ou lapaç, herbe de chiffon, nom commun à bien des molènes, du latin lapathium signifiant chiffon, ce que sont effectivement leurs feuilles laineuses) devient ainsi èrba de La Paz (en Bolivie ?) ou èrba de la patz (herbe de la paix ?). Un ferre de cavau, nom d'un lotier qui a les gousses en forme de fer à cheval, devient ferre de caveau. Un bèc-de-cese (bec-de-pois-chiche, nom d'une olive présentant un petit bec à son sommet) devient bédécézé. Les exemples de cette sorte sont innombrables et défigurent bien sûr le sens des noms, et l'orthographe élémentaire de la langue occitane source par rapport à son étymologie. On se heurte ici au manque de 
connaissances sur la langue qui la fait restituer de façon improbable, uniquement à l'oreille, et en passant par le français, au nom de ce que «les patois n'ont point d'orthographe ». Le secteur particulier qui a peut-être été le plus victime de son intérêt, est celui des noms variétaux d'oliviers. La défiguration commence très tôt, au xvIII ${ }^{\mathrm{e}}$ siècle, commise par des personnes versées en agronomie mais pas du tout en occitan, s'est poursuivie jusqu'au xxe - par exemple Ruby (1918) considéré comme «la bible » par les spécialistes de l'olivier, mais qui ne saurait l'être concernant l'occitan -, et la compilation de compilations a joué à plein jusqu'à maintenant, comme nous l'avons détaillé dans une nomenclature de quelques 280 noms variétaux en occitan (Ubaud, 2016).

7 Or, sans la moindre connaissance de la langue d'oc, comment peut-on prétendre restituer et analyser correctement ces noms? L'ignorance des mots manipulés va jusqu'à attribuer des noms féminins à l'olivier et inversement des noms masculins à l'olive, voire à les employer en sens contraire dans un même ouvrage ou chez le même auteur: tantôt l'olivier grossanne, tantôt l'olive grossan, tantôt l'olive grossan ou grossanne, en place du seul couple grammaticalement juste l'olivier grossan / l'olive grossanne. On ne greffe pas une poire et on ne mange pas un prunier, on ne presse pas un pommier mais une pomme : c'est pourtant ce qui est donné à lire à propos des olives et oliviers à peu près partout, textes de chercheurs, sites des moulins oléicoles, listes officielles publiées par l'Afidol ou le ministère de l'Agriculture ou l'Europe reproduisant les documents antérieurs.

8 La langue occitane était étrangère aux auteurs de ces ouvrages, qui n'en relevaient que les sons, sans n'y rien comprendre. Ne parlons pas des prétendus sens de ces noms relevant de la plus haute fantaisie que l'on réduira à un exemple : l'olivier bouteillan (de l'occitan botelhan) s'appelle ainsi "parce que son olive a une forme de bouteille »... Se pose alors la question: bouteille de Perrier, d'Armagnac ou de Bourgogne? Cet olivier, plus que d'autres, porte ses olives en grappes, qui se dit botelh en occitan. Hélas, la langue d'oc, qui dit l'olive et l'olivier depuis 800 ans, reste encore et toujours volontairement étrangère aux spécialistes contemporains de l'olivier (Moutier et al., 2011).

9 Un autre exemple tout aussi alarmant est celui des explications modernes à propos du nom bien connu de l'olive picholina / picholine ou pichouline, devenu par les aléas de l'histoire nom variétal. Si l'on se donne la peine de chercher, elles sont pourtant données dans plusieurs sources anciennes du XvIII ${ }^{e}$ siècle, et nous les avons un peu affinées (Ubaud, 2016): il s'agit de deux frères toscans nommés Pescholini (puis Picciolini, puis Picholini) venus s'installer au XvII siècle sur les bords de l'Étang de Berre, à Saint-Chamas (avec pignon sur rue à Marseille dans un bel hôtel particulier toujours visible), où ils ont mis au point un procédé de désamérisation de huit variétés d'olives locales (et non pas une seule, la picholine actuelle, en fait la colliasse du Gard qui n'aurait jamais dû s'approprier le nom de la préparation). Procédé tellement apprécié que tout le monde voulait de ces olives «à la Picholini / à la Pichouline " - expression encore en usage à Marseille à la fin $\mathrm{du} \mathrm{xx}^{\mathrm{e}}$ - et non "des olives picholines ». Mais curieusement, ces explications n'ont pas satisfait les spécialistes (sur le plan agricole ou génétique) de l'olivier qui ont avancé que «c'est parce que cette olive est petite ", "cette olive s'appelle ainsi parce qu'elle a une forme de cœur de pigeon » (à l'oral, picholina se rapproche effectivement de pijolina, lequel mot n'existe pas en provençal). Il suffit pourtant de regarder l'olive pour s'apercevoir qu'elle n'est ni petite ni en forme 
de cœur. Ou encore qu'elle est mentionnée "chez Tournefort, bien avant l'arrivée au XVIII siècle des frères Picciolini ", concluant que le nom de l'olive n'a rien à voir avec le patronyme, voire que les frères Picciolini n'ont jamais existé. Lesquels fabricants renommés sont pourtant localisés en plein $\mathrm{xvII}^{\mathrm{e}}$ siècle et par l'abbé Couture curé de St-Chamas - mieux placé que quiconque pour connaître l'histoire de son village, de plus auteur de deux ouvrages sur l'olivier $(1783,1786)$-, et par leur arbre généalogique détaillé, trouvable pour qui veut chercher un peu... Donc contrairement aux affirmations péremptoires, Tournefort (1700) écrit bien après les frères Picciolini. Mais il est vrai que F. Mistral se trompe lui aussi en mentionnant l'existence de ces confiseurs «dans le dernier siècle» - c'est qu'il a recopié Couture à la lettre -, donc au $\mathrm{XIX}^{\mathrm{e}}$ par rapport à lui, et en lui attribuant pour étymon l'italien picciola, petite.

Ces errements historiques et dialectaux sont écrits dans des traités de l'olivier tout à fait contemporains (Breton, 2006) et repris fatalement par d'autres. Dire que c'est un désastre autant historique que linguistique que culturel est un euphémisme, car ces ouvrages écrits par des gens connus du milieu oléicole en arrivent à contaminer jusqu'aux natifs, devenus peu sûrs de leurs savoirs et qui finissent par répéter ces erreurs "sous influence». Cela nous a amenée à écrire une lettre ouverte à une centaine d'oléiculteurs pour les alerter sur cette perte tragique de leur lexique, leur syntaxe et la sémantique associée aux noms de nos olives/oliviers. L'effet compilation sans science ni conscience n'a fait que s'accentuer pour la période postmistralienne : on compile dans le dictionnaire de Mistral tout ce qui a trait aux plantes (c'est un sujet qui plait), et il s'est publié et se publie encore à peu près partout des petits lexiques mélangeant sans distinction noms alpins, provençaux, languedociens, rouergats, gascons, etc., qui sont bien sûr repris en cascades par les divers écriveurs de l'occitan. Mais, comme s'il n'y avait pas déjà suffisamment d'embûches, il faut ajouter en plus un problème général concernant tous les écrits, surtout ceux antérieurs au $\mathrm{xx}^{\mathrm{e}}$ siècle : les coquilles d'éditeurs. Combien deç transformés en $s$, de $b$ inversés en $p$, de $r n$ transformés en $m$ ou réciproquement, venant se superposer aux écritures déjà fausses des auteurs. Les traités sur l'olivier abondent particulièrement en coquilles de ce genre : courmau pour cournau (qui fait perdre la référence à la cornouille, còrna ou còrnia, olive allongée comme ce fruit), galliningue pour gallinenque, rapugete pour rapuguette, et le plus comique de tous répugnan pour rapugan (de rapuga, grappe, donc encore un olivier ayant ses olives groupées en grappe comme le botelhan). Ces doubles faux d'auteurs et/ou d'imprimeurs sont religieusement recopiés par des compilateurs ne connaissant visiblement rien à la langue d'oc. Mais ces noms sont si «amusants ", n'est-ce pas?

\subsection{Les atlas linguistiques}

Qu'en est-il du côté des atlas linguistiques? Hélas, tout aussi approximatifs voire totalement erronés dès que l'on touche à quelques subtilités botaniques (subtilités pour des ignorants, mais évidences premières pour des botanistes). La présentation des travaux de Gilliéron et Edmont sur le site du CNRS (<http://lig-tdcge.imag.fr/ cartodialect5/\#/>) est bien vague : "L'Atlas linguistique de la France (ALF) a été réalisé par Jules Gilliéron et Edmond Edmont. Entre 1897 et 1901 Edmond Edmont a effectué des enquêtes de terrain dans 638 communes de la France. Pour ce faire, il a utilisé un questionnaire composé de notions qu'il a posé auprès de 735 informateurs. » 
Qu'appelle-ton "enquêtes de terrain»? L'informateur a été enquêté physiquement mais lui a-t-on fait rencontrer sur le terrain les plantes listées en questionnaire ? Sujets autrement plus épineux que de répondre aux questions sans équivoque "il pleut, averse, tempête, rosée, carotte ». Au vu des noms récoltés pêle-mêle et sans discrimination d'espèces, on ne peut qu'avoir les plus grands doutes... Pour des atlas plus récents, ALLOR, ALP, il nous a été dit que c'est parfois (toujours?) un questionnaire laissé à l'informateur - et toujours pas une enquête sur le terrain montrant les plantes en question - qui a conduit à la restitution des noms. Chose que nous ignorions au départ et qui explique le nombre important de cartes erronées ou très approximatives, ce dont un botaniste s'aperçoit immédiatement. Par exemple, la carte 38 « Chêne » ci-dessous interprétation de la carte $n^{\circ} 265$ de l'Atlas linguistique de la France (ALF), comme les cartes "Genévrier ", "Plantain ", "Silène enflé » et bien d'autres de l'Atlas linguistique de Provence (ALP) ou encore la carte $\mathrm{n}^{\circ} 162$ «Plantain » de l'Atlas linguistique du Languedoc oriental (ALLOR), qui interpellent grandement. Nous allons nous y attarder car leur analyse vaut pour bien d'autres cartes botaniques.

Figure 1. - Carte n 38 « Chêne » (Le Dû et al., 2005), s'appuyant sur la carte ALF n 265 " Chêne » de Gilliéron et Edmont (1902-1910).

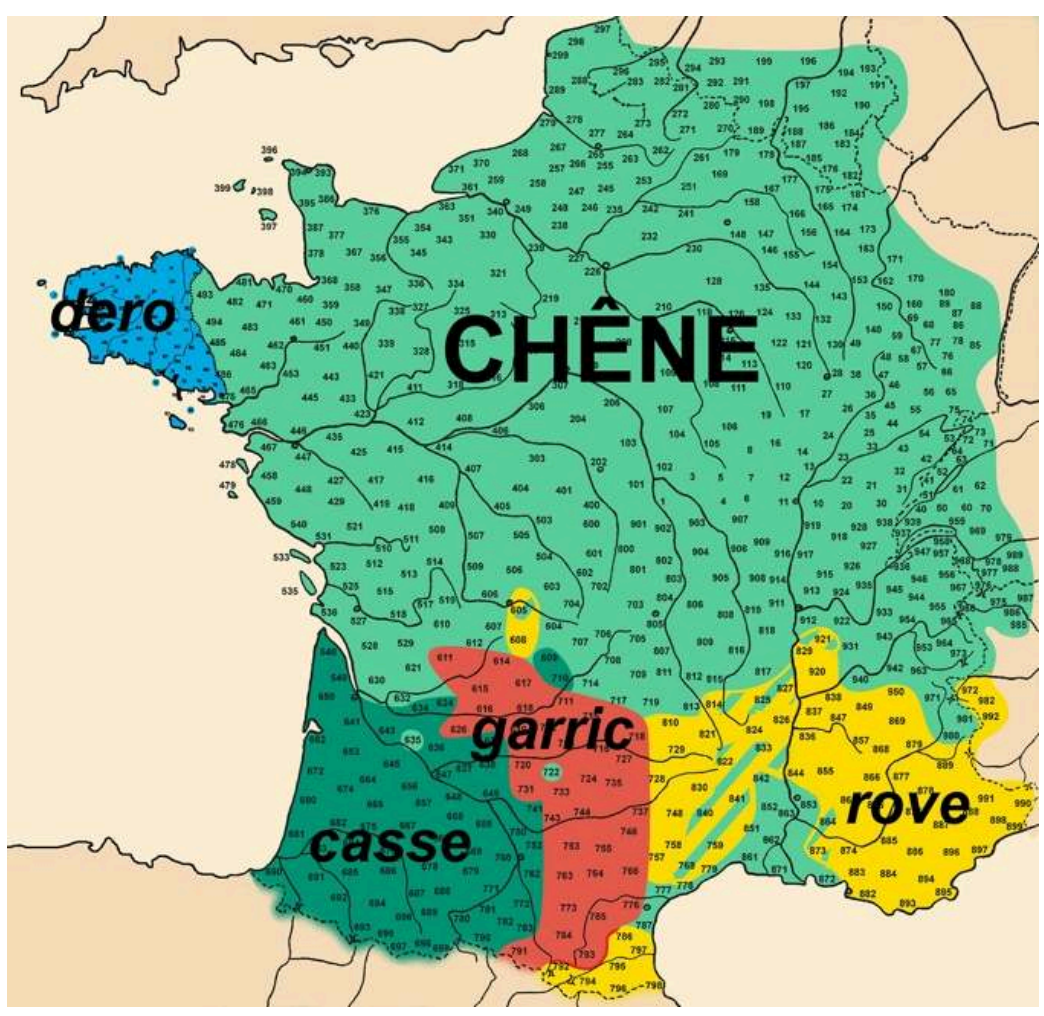

Cette carte reprend la carte primitive $n^{\circ} 265$ "Un beau chêne » de l'ALF (Gilliéron \& Edmont, 1902-1910) qui ne présentait pas ces aires lexicales, mais seulement six à huit points d'enquêtes par département, ce qui est bien peu pour en tirer des conclusions. Nous ne pouvons la restituer ici, car elle n'est lisible qu'en très grand format (<http:// lig-tdcge.imag.fr/cartodialect5/\#/visualiseur>). On y retrouve les noms occitans de nos quatre chênes sur la même carte - y compris le francisme chaine très répandu pour le Chêne blanc -, mais usant du signe + pour distinguer le Chêne vert (euse +, euve +, par exemple points $840,864,894$ ), et du signe $\neq$ pour le Chêne-liège (suve $\neq$, suvera $\neq$, points $894,897,899)$, mais sans analyse critique des réponses suve et suvera qui 
désignent le liège et non le Chêne-liège. Et une seule mention du Chêne-kermès avaus au point 874 , ce qui est plus qu'indigent, ce chêne existant pourtant partout en terres calcaires. Mais il rentre difficilement dans l'esprit de la question posée «Un beau chêne", car il atteint au maximum 2,50 m: cela a peut-être retenu les autres informateurs dans leur réponse.

Si la présentation de l'ALF est peu pertinente, peu rigoureuse, à cause du singulier " le chêne » de l'intitulé de la carte, il y a au moins conscience de l'existence de chênes différents en terres occitanes. Par contre, la reprise de cette carte (Le Dû, Le Berre, Brun-Trigaud, 2005) pour un "essai d'interprétation des cartes de l'Atlas linguistique de la France » dénature encore plus la réalité, ne laissant apparaître que le lexique d'un seul type de chêne, ceux à feuilles caduques, mais non précisés pour autant. Elle fait déduire aux lecteurs une différenciation géographique en terres occitanes casse / garric / rove nettement marquée : or le(s) chêne(s) nommé(s) garric ou casse ne sont pas le chêne nommé rove / rore.

15 De même au vu de l'aire de couleur jaune, les lecteurs déduisent que rove s'emploie aussi dans l'ouest du Languedoc: rove est totalement inconnu dans l'Hérault par exemple. C'est méconnaître la forme rore et ses variantes roire, roeire, pourtant extrêmement répandues, présentes chez tous les auteurs occitans et en toponymes (au contraire de la forme rove bien provençale), et notées dans la carte primitive de Gilliéron. Ajoutons encore que le rove au nord du domaine marqué en jaune n'est pas le rove du sud du domaine. Cette image colorée, pour tenter d'être plus parlante, de cet ALF réinterprété est donc totalement erronée et ne fait que brouiller encore plus les pistes par rapport à la carte primitive. C'est que le titre au singulier "chêne » est une question fermée, car un intitulé que nous qualifierons à la hâte de littéraire (i.e. non botaniste) ne soupçonnant pas que "chêne » sans déterminant n'a strictement aucun sens en terres d'oc. Or, quel que soit le sujet d'enquête, il ne faut bien évidemment pas appliquer sa grille de lecture de son territoire (ou son lexique) à tous les autres territoires. En terres «nordiques ", il n'y a que des chênes à feuilles caduques qu'on peut, à la hâte, ranger sous l'étiquette unique de "chêne ». En terres sud-occitanes, il faut préciser impérativement, sous forme de questions claires, "Chêne blanc, Chêne vert, Chêne-kermès, Chêne liège ", tous quatre bien différenciés lexicalement (nous ne rentrons pas ici dans les détails des variantes dialectales au sein d'un même parler): soit dans l'ordre rore (l.) / rove (p.) ; euse, ausina (1.) / euse, euve (p.) ; avaus, garrolha (1.) / agarrús, garrús (p.) ; siurièr (l.) / suvier (p.). L'intitulé correct de la carte eut donc été "chênes à feuilles caduques" pouvant regrouper plusieurs espèces assimilables esthétiquement et botaniquement pour des non spécialistes (Quercus humilis pour le Sud, Q. robur, Q. petraea ailleurs). Encore manque-t-il le Chêne tauzin (tausin) dans le Sud-Ouest, bien particulier avec ses grosses cupules hérissées, et non répertorié, ainsi que les noms basques. Nos quatre chênes méditerranéens sont par contre correctement restitués dans l'ALLOR, disposant chacun de sa carte parfaitement exploitable, aux erreurs possibles près des informateurs, mais non analysées comme telles par les enquêteurs.

La carte "Genévrier" de l'ALP pèche exactement par le même défaut: poser la question « comment appelez-vous le genévrier? » est encore une question fermée qui ne veut rien dire puisque, comme pour les chênes, les différents genévriers sont parfaitement distingués lexicalement car parfaitement identifiés. Ginebrier et variantes pour Juniperus communis, cade et variantes pour J.oxycedrus, sabina, morven pour 
J. phoenicea, sabina pour J. sabina. Si la question est posée face à la plante, une enquête sérieuse eut été de compléter par « connaissez-vous d'autres genévriers et comment les nommez-vous? ». Si la question a été posée par écrit, il est évident que l'informateur répond avec la première idée qui lui vient à l'instant où il se penche sur sa feuille, et surtout en fonction de son milieu, donc ce qu'il considère comme son référentiel en matière de genévrier. Un Camarguais répondra morven car il n'y a pas d'autres genévriers en Camargue ; un habitant des garrigues écrasées de chaleur répondra cade et morven, car il n'y a pas les autres genévriers sur son territoire ; un habitant des ubacs et des hauteurs dira ginebrier, et un montagnard sabina qui n'existe effectivement qu'en montagne. Mais sabina en garrigue nomme aussi Juniperus phoenicea dans l'Aude par exemple: on se gardera d'en déduire que c'est la même espèce que la sabine des montagnes. Certains, au contraire, connaissent sur leur territoire deux ou trois espèces de genévriers, et le précisent immédiatement. C'est donc l'ignorance de l'enquêteur sur le sujet botanique qui sert de méthodologie... Là encore, une approche sérieuse eut été de faire quatre cartes différentes pour y constater l'unanimité des appellations ou au contraire les différenciations géographiques, espèce par espèce : genebrier, ginebrier, genibrier, etc., pour Juniperus communis ; sabina, morven, cade morvís, etc., pour Juniperus phoenicea ; cade, chai, etc., pour Juniperus oxycedrus. Là aussi, le thème est parfaitement traité dans l'ALLOR: une carte pour J.communis, une carte réunissant J. oxycedrus et J. phoenicea mais présentant les noms nettement séparés par un point-virgule à chaque point d'enquêtes. Il n'y a donc aucune confusion possible.

La carte intitulé «Le plantain» de l'ALP montre encore le même manque de méthodologie issu de la même méconnaissance botanique. En botanique «le plantain » ne veut rien dire : il y a beaucoup de plantains, fort différents et visuellement et dans les usages. Jean-Pierre Lai (Université Grenoble Alpes) nous a adressé un article de Michel Contini (1986) qui relevait déjà ces incohérences :

Prévue initialement pour figurer dans l'un des premiers volumes de l'Atlas Linguarum Europae, la carte Plantain n'aura pas en définitive cet honneur. La raison principale en est que les atlas nationaux, constituant la source première de l'A.L.E., laissent apparaître une profondeur inégale des enquêtes, soit pour ce qui concerne le nombre de localités ayant donné une réponse positive, soit pour la précision de cette dernière concernant notamment l'identification de telle ou telle variété de la plante. Car le terme générique de Plantain couvre en réalité un grand nombre de variétés de la famille des Plantaginées, dont les types Plantago major et Plantago lanceolata sont les plus fréquents. L'étude de leur désignation dans les parlers romans se heurte à une difficulté majeure. Dans la plupart des atlas de première génération [...] mais aussi de deuxième génération [...] les questionnaires prévoient une seule question générique Plantain, censée couvrir la totalité de l'espèce. (p. 67-88)

On notera que le nombre pas assez élevé de localités est cependant un péché bien véniel eu égard à l'absence d'identification des espèces sur le terrain. Car si le diagnostic est bien posé, et le texte mis en exergue sur la carte de l'atlas ne fait que l'affirmer, l'auteur ne va pas jusqu'à formuler le problème crucial de l'absence de botanistes dans les projets des atlas quels qu'ils soient. De plus, les erreurs de vocabulaire de son propre texte, "variété » en place de "espèce ", puis "totalité de l'espèce " (par définition unique) en place de "totalité du genre" (par définition multiple sauf très rares exceptions), montrent encore une méconnaissance du lexique de la botanique qui est décidemment une science bien étrangère à beaucoup de gens qui pourtant en parlent d'abondance. 
19 dialectaux plus qu'incertain, l'auteur reprenne le singulier « plantain » de l'atlas pour nommer son analyse (Les désignations du plantain dans les langues romanes), en mentionnant souvent les incertitudes : de quelle espèce parle-t-on dans ces atlas pour ce nom-là? On est donc forcé de spéculer sur des données floues. Si de plus le «spéculateur " n'a peu ou pas de notions d'ethnobotanique occitane - qui permet parfois de conclure clairement sur l'appartenance de tel nom à telle espèce et pas telle autre-, le résultat final devient encore plus emmêlé que l'écheveau de départ. Qu'y-a-t'il en effet de plus différent qu'un Plantago lanceolata aux feuilles allongées et à cinq nervures (èrba de cinc còstas [l., p.]) plante vulnéraire et comestible, un Plantago major des zones fraîches voire humides aux très larges feuilles à 7 nervures et dont les épillets longs et raides (comme queue de rat) sont toujours donnés aux oiseaux ce qui justifie ses noms (èrba de sèt còstas (1.), èrba de canaris, grana de canaris, planta de canaris (p.), èrba de la calha (p.), coga de rat (1.)), un Plantago holosteum aux très petites feuilles en alène et à usage traditionnel chez les bergers, en application ou en bouquets thérapeutiques suspendus dans les bergeries (èrba de san cap, i. e. herbe de la tête saine, en Cévennes gardoises), un Plantago coronopus aux feuilles découpées comme les ramures d'un cerf (bana de cèrvi), salade comestible toujours récoltée (et même mise en culture), un Plantago cynops des zones sèches, sous-ligneux en touffe ronde et aux feuilles filiformes, vulnéraire lui aussi (badasson (p.)), et bien d'autres espèces encore? Par contre, l'étude de l'auteur sur les images utilisées entre les différentes langues romanes pour parler DES plantains, est fort intéressante, malgré les approximations de l'ALP et semble-t-il des autres atlas des pays voisins aussi peu soucieux de précisions botaniques.

Qu'en est-il du côté de l'ALLOR ? Guère mieux puisqu'on retrouve le titre au singulier «Plantain» (carte $\left.\mathrm{n}^{\circ} 162\right)$, assorti toutefois de la précaution oratoire : «Les mots de la carte s'appliquent en principe à tout le genre Plantago sans distinction d'espèces. Lorsque celles-ci sont distinguées lexicalement, les mots sont suivis d'une lettre: L (pour Plantago lanceolata), M (pour Plantago major)». On appréciera comme il se doit le «en principe »... Si la séparation sémantique à l'aide des lettres $\mathrm{L}$ et $\mathrm{M}$ est louable, malheureusement elle n'est guère appliquée sur la carte. Et elle est mise à bas par la volonté de dégager cependant des grandes aires : une aire coa de rat côtoie une aire èrba de cinc còstas laquelle montre des points d'enquêtes avec grana ou èrba de canaris. La précaution oratoire n'a pas été appliquée, car èrba de cinc còstas (herbe à cinq nervures) ne concerne que Plantago lanceolata ou P. minor; coa de rat (1. : points 12.31, 07.02, 30.31), coga de rat (1.: point 34.03), èrba de canaris (1.: points $34.13,34.15,34.21)$ et grana de canaris (1. : point 11.18, 34.11, 34.21), que Plantago major.

21 Là aussi on procède encore à un mélange botanique et lexical erroné, car on prétend dégager des aires d'appellations majoritaires pour deux taxons différents mentionnés aux points d'enquêtes. Il fallait donc faire une carte «Le Plantain lancéolé » et une autre carte "Le grand Plantain » sur lesquelles on peut alors dessiner des contours d'aires. Seule la zone plantatge (l., 11) (<latin plantago) peut être estimée comme s'appliquant «en principe » à tous les plantains. Quant au vocable aurelha de lèbre n.f. (l., p.) (oreille de lièvre), nous estimons, au contraire de Michel Contini, qu'il s'applique à Plantago lanceolata aux feuilles très rétrécies à la base, comme le sont les longues oreilles de l'animal, et non à Plantago major bien trop larges pour y faire référence. Pour aurelha d'ase (p.), le doute subsiste entre ces deux espèces. Remarquons aussi que pour 
les auteurs, il n'y aurait que Plantago lanceolata et major illustrant le genre Plantago. Or, le genre comprend une trentaine d'espèces, certes pas toutes sur les territoires concernés par l'ALLOR, mais de là à le réduire à deux seulement... Il conviendrait d'ouvrir une flore de temps en temps et aucun botaniste n'aurait procédé ainsi. Jacques Barrau, botaniste et anthropologue, pointait cette incohérence méthodologique lors d'un congrès sur les savoirs naturalistes de Sommières en 1983 :

Faire apparaitre la trame végétale et animale de l'histoire des sociétés et civilisations [...] implique tout de même que l'on connaisse quelque chose des objets et phénomènes naturels en cause ou que l'on s'assure le concours compréhensif de quelque naturaliste éclairé, c'est-à-dire ne souffrant pas de totale allergie aux faits de culture et de société ; ça existe, j'en ai rencontré ! (p. 5-12)

Nous le citerons encore car nous partageons entièrement son point de vue.

Figure 2. - Carte « Plantain » de l'ALLOR (carte $\left.n^{\circ} 162\right)$ et ses contradictions.

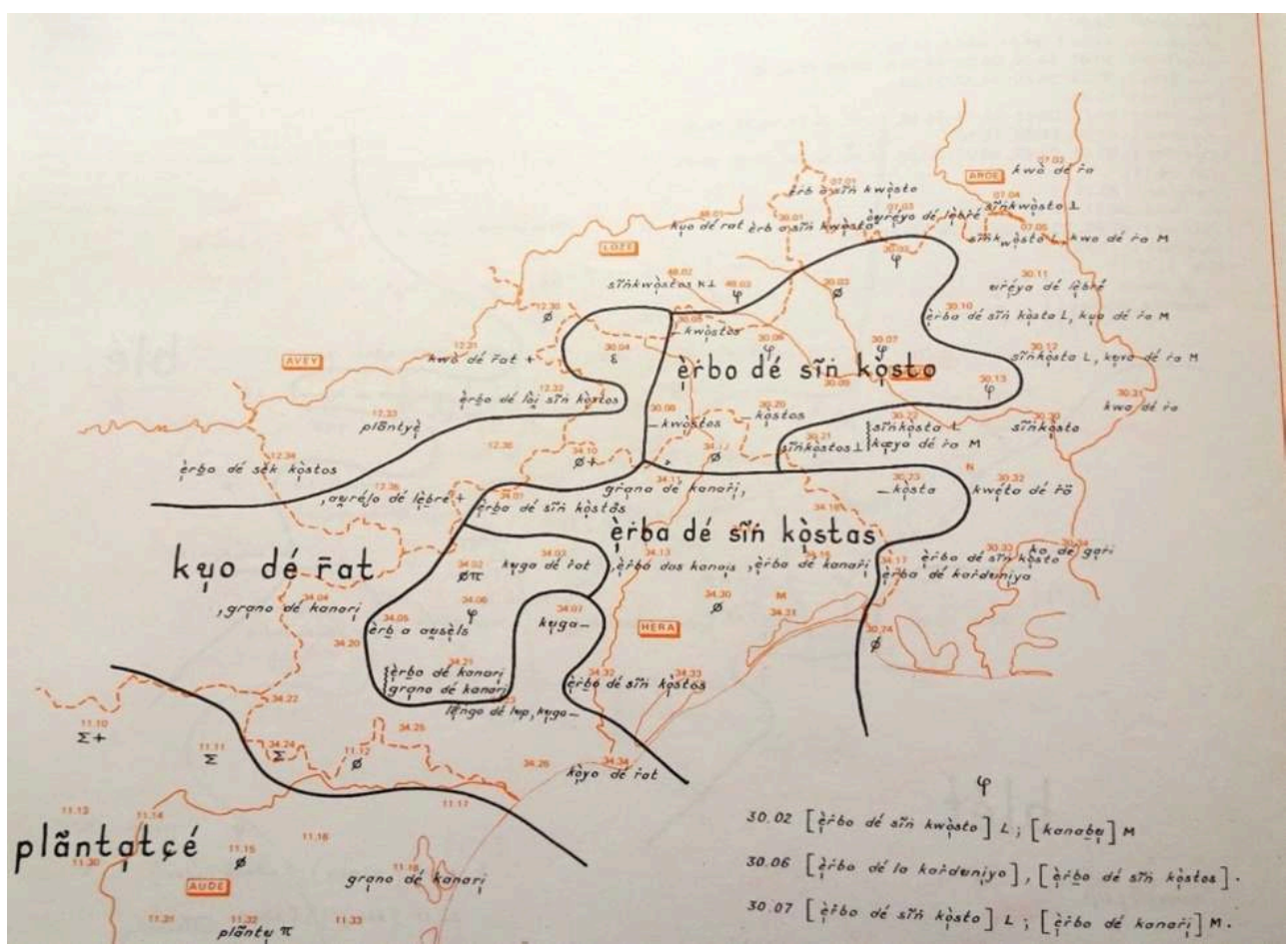

J. Boisgontier (1981-1986), Atlas linguistique et ethnographique du Languedoc oriental (ALLOr), Paris, CNRS, 3 vol. 
Figure 3. - Plantain lancéolé (Plantago lanceolata) - Ėrba de cinq còstas, Aurelha de lèbre.

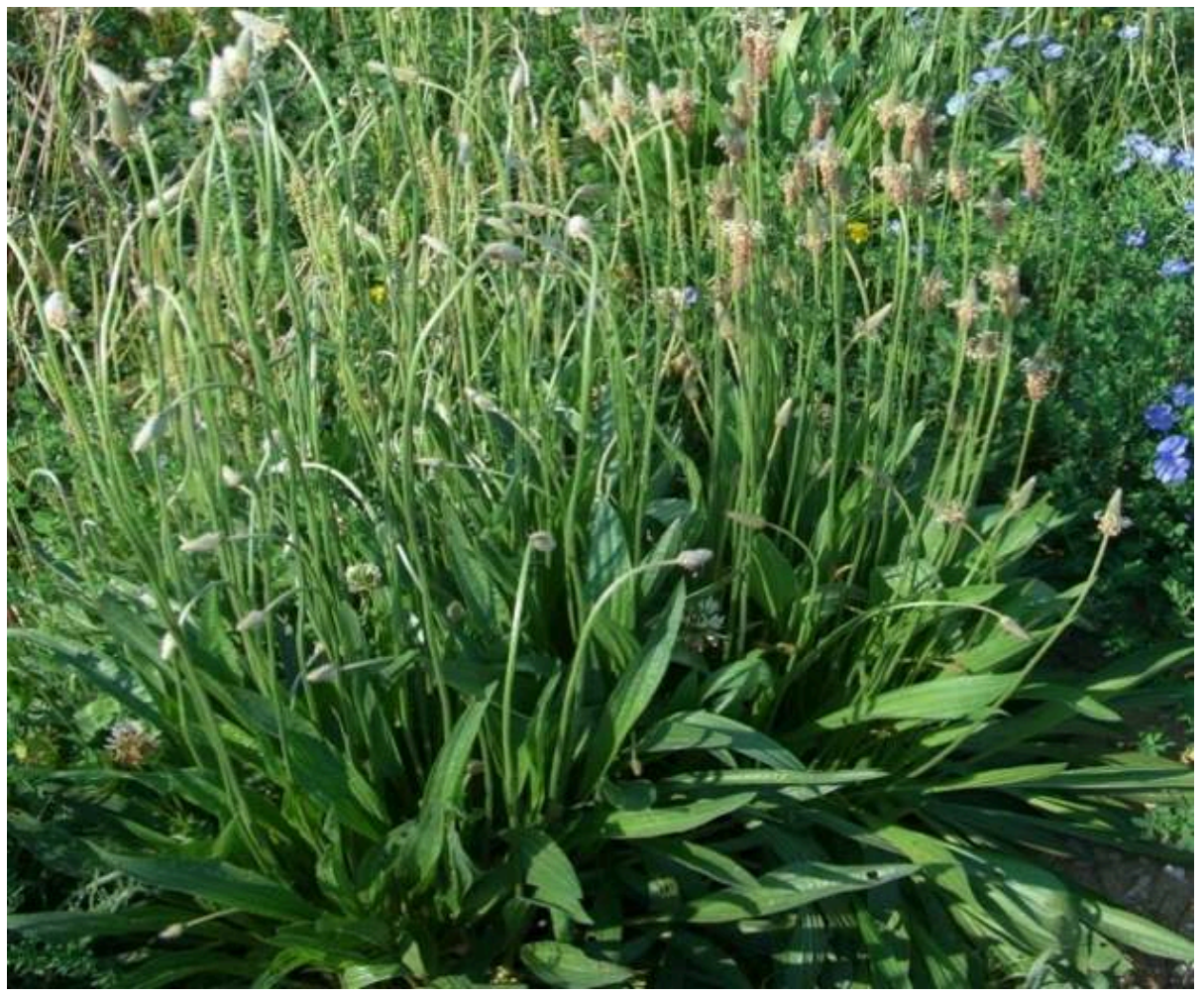

Photo : Josiane Ubaud.

Figure 4. - Grand plantain (Plantago major) - Ėrba de sèt còstas, Grana de canaris, Coa de rat.

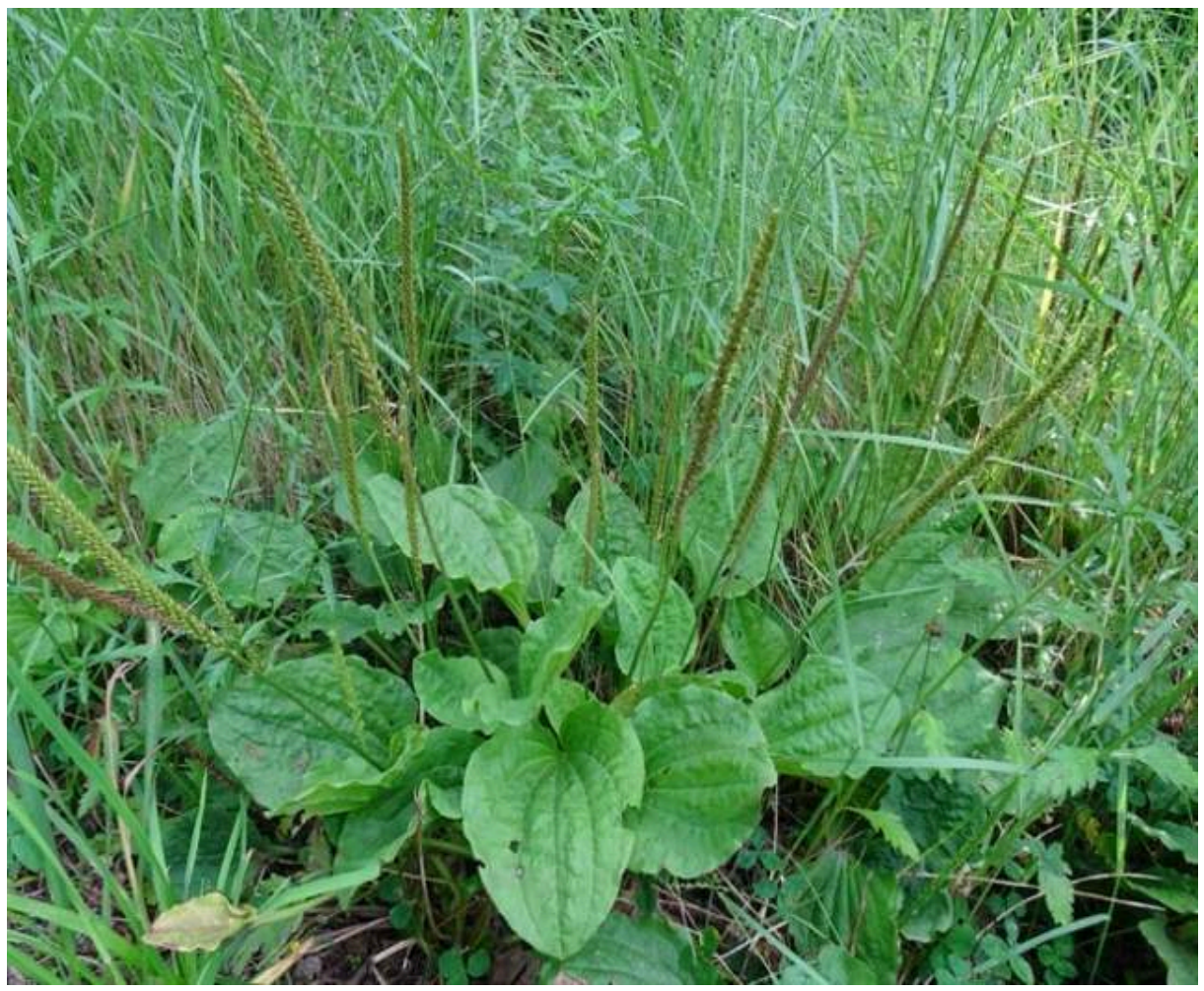

Photo : Josiane Ubaud. 
Figure 5. - Plantain corne-de-cerf (Plantago coronopus) - Bana de cèrvi.

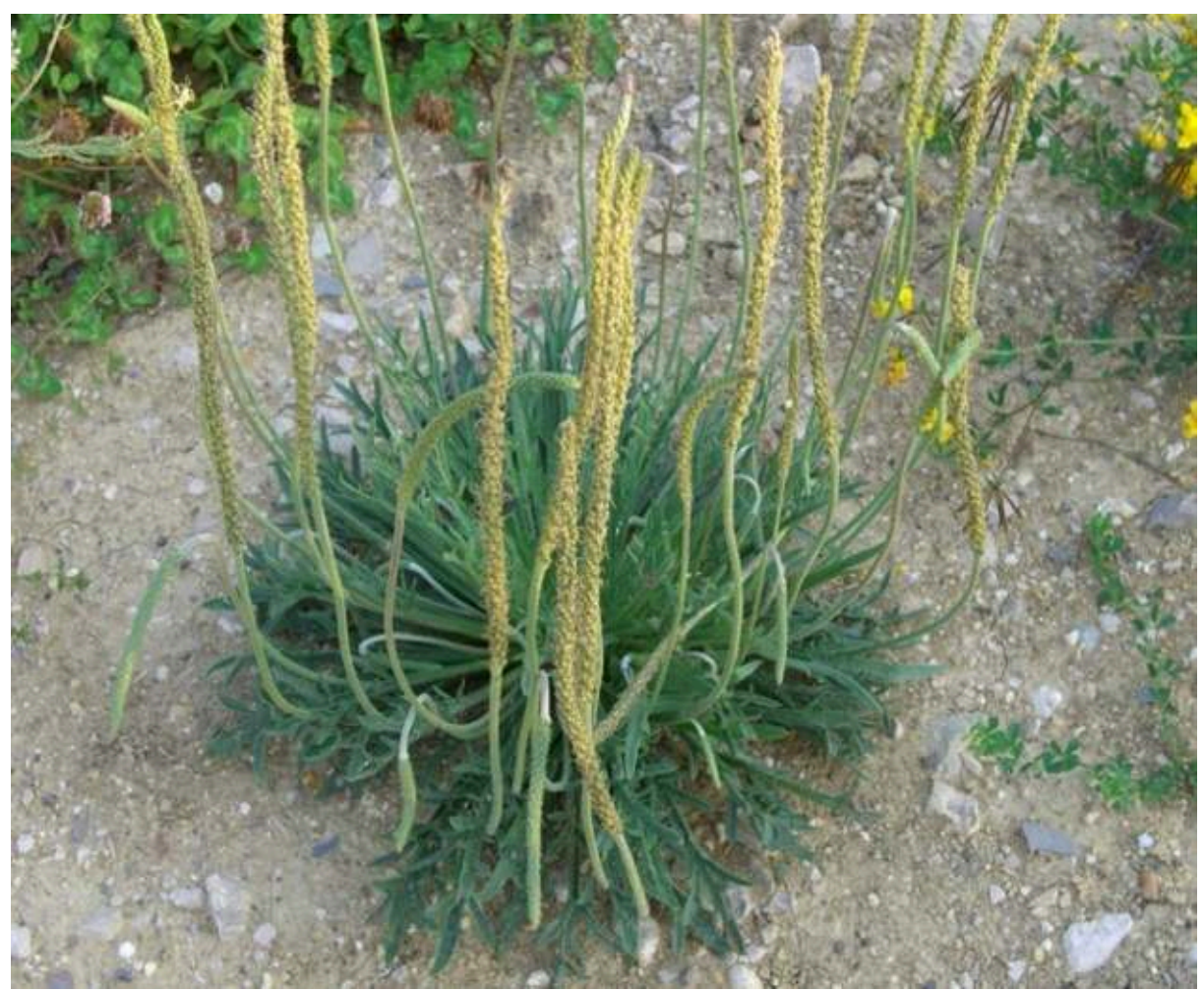

Photo : Josiane Ubaud.

Figure 6. - Plantain des chiens (Plantago cynops) - Badasson.

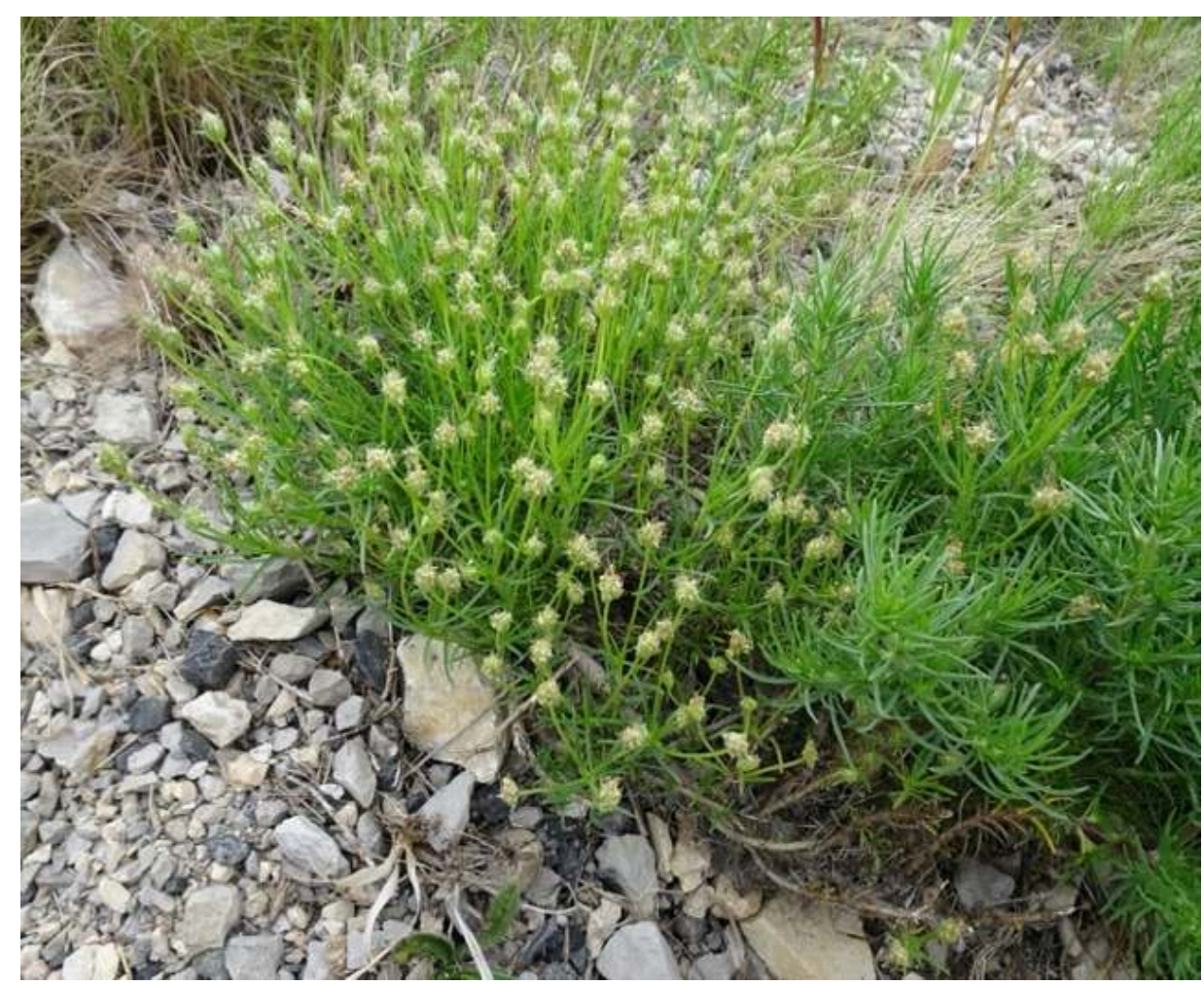

Photo : Josiane Ubaud. 

Silène enflé (Silene vulgaris, ex Silene inflata) et on aurait dû avoir une carte fiable. Malheureusement, c'est ici l'absence d'ethnobotaniste au fait de la langue d'oc concernant les phytonymes qui a mené à enregistrer sans sourciller morcible comme un nom possible (ce nom désigne l'Ellébore fétide, plante toxique), ou encore lachuscla et variantes chuscla, juscla (nom générique des euphorbes, autres plantes toxiques). Si on se perd en conjectures sur l'apparition de l'ellébore dans cette enquête (aucune ressemblance possible avec le silène), on croit comprendre la présence erronée de l'euphorbe, plus exactement Euphorbia serrata: les très jeunes pousses de cette euphorbe peuvent passer pour celles du silène aux yeux de néophytes, nous l'avons souvent constaté en sorties botaniques. Mais l'euphorbe, toxique, contient du lait (d'où son nom sur le radical lach-), pas le silène, plante comestible. Ici, la plante a-t-elle été vraiment montrée, mais par erreur par l'enquêteur pas assez compétent en botanique et la prenant pour le silène? Auquel cas l'informateur a répondu à raison lachuscla puisque cela en était bien une. Personne n'a donc visiblement songé à interroger la validité de ces réponses à la question « Silène enflé » en allant voir l'entrée « lachusclo » chez Mistral ? D'autant que les autres points de l'ALP donnent des bonnes réponses que l'on relève d'ailleurs encore partout, en Languedoc comme en Provence: petarèl, petarèu, petarèla, petard, car les enfants font éclater (petar) les calices sur le dos de leurs mains.

Figure 7. - Silène enflé (Silene vulgaris) - Petarèl, Petarèla.

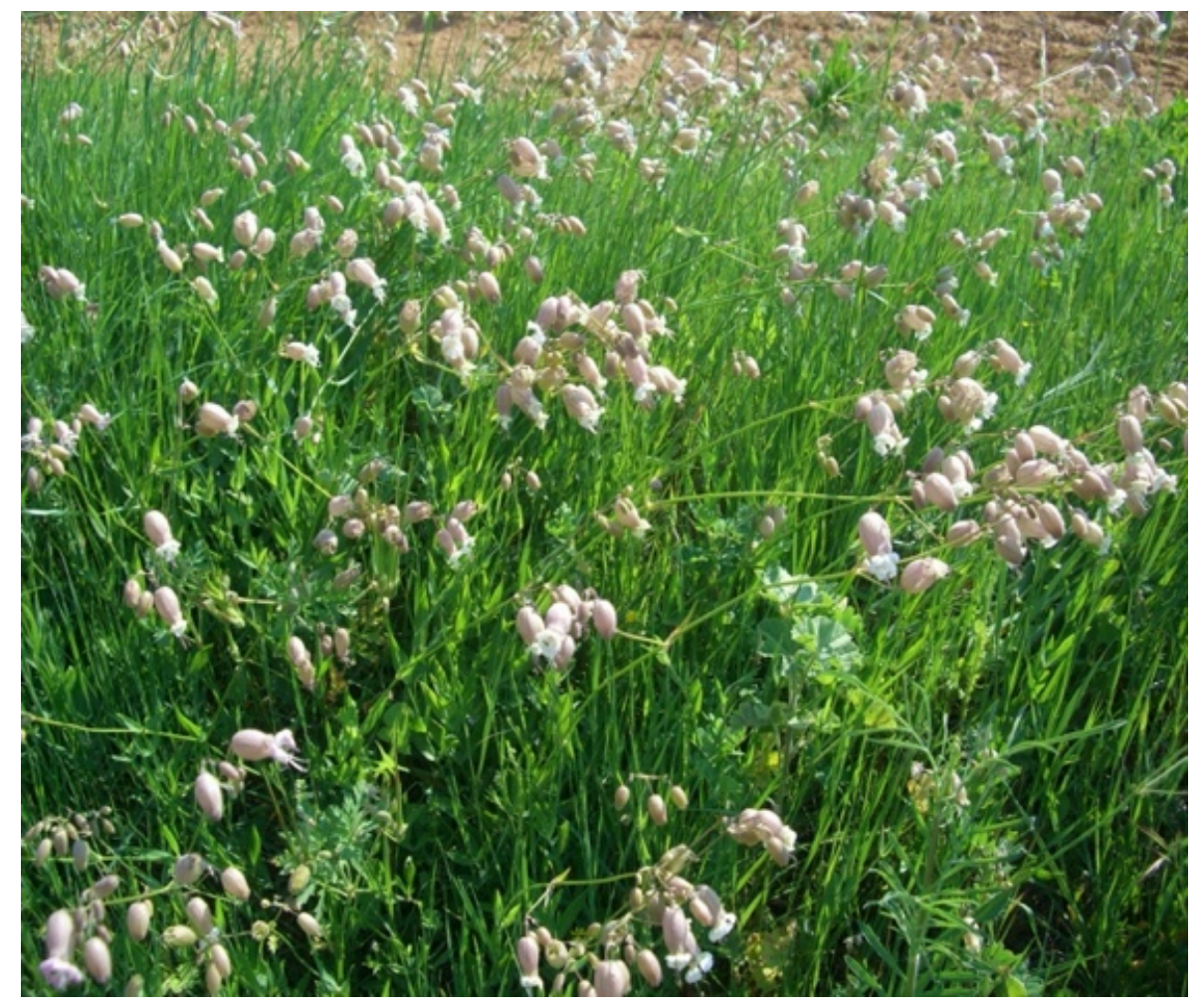

Photo : Josiane Ubaud.

Le choix des noms de plantes a donc été fait sans les connaissances botaniques élémentaires des espèces, ni de leur répartition sur le terrain, ni de la spécificité des paysages, ni de la classification populaire. Or, comment peut-on appréhender les 
réponses des informateurs occitanophones si les enquêteurs francophones sont visiblement ignorants sur le sujet déjà dans leur propre langue? Il en résulte une représentation de tous ces noms réunis sur une même carte alors qu'ils ne désignent pas du tout le même taxon, même s'il est dit dans un coin de l'atlas « qu'il y a plusieurs genévriers, plusieurs plantains ». Si bien des végétaux ne présentent pas d'ambiguïté comme pommier, poirier, figuier, cyprès, buis, coquelicot, thym, bleuet, avoine, carotte, sauge, sarriette, salsepareille, romarin, etc., il n'en est pas de même pour bien d'autres comme chêne, genévrier, cornouiller, peuplier, érable, pin, sorbier, pistachier, fillaire, plantain, lavande, etc., qui ne sauraient être réduits à un taxon et dont il convient de préciser impérativement le nom d'espèce. Ces cartes ont donc induit en erreur des générations d'étudiants, de dialectologues, de botanistes, arguant du fait que «puisque c'est restitué dans les atlas du CNRS, c'est donc fiable», et se dispensant ainsi d'analyses approfondies.

\subsection{Les écrits littéraires et almanachs}

Les écrits littéraires, en prose, en vers, ou écrits dits d'almanachs constituent d'autres sources qu'il faut également analyser avec circonspection quant à la déduction sur l'origine géographique des phytonymes. On y constate aussi des emprunts à des dictionnaires, pas forcément représentatifs du parler de l'auteur. Diverses raisons se présentent : méconnaissance par l'auteur du nom de telle plante qu'il va donc chercher dans un lexique à portée de main (effet retour des dictionnaires, particulièrement chez des auteurs récents ayant perdu le contact avec la nature et son lexique), griserie du lexique qui fait préférer tel mot à tel autre pour sa sonorité, mais ne saurait donc être une preuve dialectale de ces paroles, accumulation de noms de plantes sur un même lieu, complètement invraisemblable écologiquement parlant. Par exemple, si Mistral est très fiable quant à la flore de Crau et de Camargue évoquées dans son long poème Mireio, il est beaucoup moins réaliste dans l'épopée de son héros Calendau.

D'autres auteurs sont aucontraire indéniablement des témoins lexicaux de leurs dialectes - comme pour les salades sauvages qui furent honorées de nombreux poèmes car vécues à juste titre comme marqueurs culturels, chacun rivalisant pour égrener le plus de noms possibles -, et pour bien d'autres végétaux lors de la description des paysages où vivaient ces auteurs. À titre d'exemples limités, sont ainsi fiables : Édouard Marsal pour le parler montpelliérain, Jean-Baptiste Fabre pour le languedocien oriental, Jean-Baptiste Gaut et Lazarine de Manosque pour le provençal central, Frédéric Mistral et Joseph d'Arbaud pour la flore de Camargue. Ou encore l'Aveyronnais Enric Mouly, connaisseur accompli de son parler rouergat et des faits naturalistes, dans la monographie de son village Complibat (1977), où de nombreuses plantes de ce canton de l'Aveyron sont scrupuleusement répertoriées avec leurs noms occitans. Les témoignages d'almanachs sont bien plus fiables aussi, car écrits par des gens " du cru » ne cherchant aucun effet littéraire, mais témoignant simplement de pratiques de cueillettes ou de l'état de leurs paysages car y baignant dedans. Les multiples almanachs publiés au XIX ${ }^{e}$ siècle, L'Armana prouvençau, Lou Bartavèu, Lou Cacho-fio, La Cigalo narbouneso, etc., réunissant des auteurs très locaux, sont donc des sources intéressantes sur le plan de la phytonymie et de sa localisation. 


\subsection{Les informateurs}

Enfin, l'autre source précieuse est évidemment celle des informateurs... lorsqu'il en reste. Certains avouent de prime abord "ne plus savoir parler la langue », mais au bout de quelques minutes, le lexique enfoui leur revient, quitte à ce que soit sous sa forme francisée. Nous avons souvent constaté cela chez les vignerons qui est un de nos sujets d'étude en particulier: " mon père ne parlait qu'occitan pour la vigne, mais moi j'ai oublié ». Il suffit de poser les questions précises «nom de la rangée droite de ceps, de la rangée oblique, de la rangée la plus courte ? ", et les noms reviennent, l'un entraînant l'autre, mais prononcés à la française, donc vécus parfois comme non occitans par les interlocuteurs. Bien sûr, il faut s'assurer au préalable d'où parle l'informateur pour pouvoir noter la localisation (du village où il vit actuellement ou d'un autre lieu où il vivait avant et dont il a possiblement transporté le lexique).

C'est donc dans ce parcours un peu labyrinthique qu'il s'agit d'analyser le corpus des phytonymes occitans, avec des sources écrites incomplètes (les dictionnaires du XVIII ${ }^{\mathrm{e}}$ siècle sont pauvres en ce qui concerne la botanique), absentes (peu de lexiques réalisés par canton par exemple) ou erronées. En ce qui nous concerne, nous sommes peu portées sur la collection brute pour publier un livre de plus de compilation de compilations, mais bien plus tournée vers l'analyse théorique de ces phytonymes pour montrer la pertinence d'une civilisation héritière des Grecs et des Latins, tant dans les usages que dans le lexique, dans une région particulièrement favorisée avec ses 4500 espèces végétales. Le retour sur l'humain confronté à ce foisonnement vert ne pouvait être que plus riche, par rapport à des régions plus pauvres floristiquement parlant. Rappelons quelques chiffres parlant en nombre de taxons (chorologie départementale) pour bien faire comprendre la spécificité de la zone méditerranéenne qui contient les $3 / 4$ de la flore française :

\begin{tabular}{|l|l|}
\hline Alpes-Maritimes $06: 4369$ & Loir-et-Cher $41: 1664$ \\
\hline Var $83: 3811$ & Aube $01: 1741$ \\
\hline Alpes-de-Haute-Provence $04: 3709$ & Meuse $55: 1783$ \\
\hline Bouches-du-Rhône $13: 3364$ & Mayenne $53: 1788$ \\
\hline Aveyron $12: 3316$ & Charente $16: 1874$ \\
\hline Gard $30: 3241$ & Nord $59: 1953$ \\
\hline
\end{tabular}

Les botanistes professionnels ou amateurs européens ne s'y trompent point, eux qui viennent arpenter nos espaces à la recherche de nos plantes spécifiques, et pour certains, de leurs noms spécifiques en langue d'oc et de leurs usages. Mais la perte de la langue imposée par l'État depuis des siècles a fatalement généré des incendies irrémédiables de bibliothèques chez les détenteurs de ces savoirs, donc des pertes de lexique faute de pratiques quotidiennes avec d'autres interlocuteurs (en dehors des effets de l'âge chez ces informateurs tous âgés), des pertes d'identifications et des pertes d'usages. Nos enquêtes de terrain nous montrent de nombreuses plantes «sans nom » : l'ont-elles toujours été ? Nous sommes frappées cependant de relever malgré 
tout quelques noms absents de tous les ouvrages, par exemple la caboçuda pour Brachypodium retusum à Montpeyroux et Viols-le-Fort (34), herbe rase et sèche bien connue des bergers, appelée ailleurs bauca. C'est dire tout ce qui a été irrémédiablement perdu.

\subsection{Les traducteurs}

L'autre domaine où la fiabilité est bien mouvante concerne celui des traductions, auteurs se traduisant eux-mêmes ou traduits par des traducteurs extérieurs. Les dictionnaires bilingues $\mathrm{du} \mathrm{xIX}^{\mathrm{e}}$ siècle supposent une compétence pour établir l'équivalence «tel nom occitan = telle(s) plante(s) ». À ce titre, nous ne pouvons avoir des certitudes sur toutes les entrées restituées par Mistral. Quel était le réseau d'informateurs qui a inspiré Mistral dans la réalisation de son dictionnaire?

Reprenons un exemple cité plus haut: nous n'avons aucun moyen de vérifier si «jauneto $=$ Trigonelle corniculée, chlore perfoliée, lotier corniculé, lichen des arbres fruitiers ", nous sommes tous obligés de lui faire confiance. Par contre, pour d'autres cas, les erreurs sont évidentes mais contaminent cependant bon nombre de lecteurs « innocents en botanique ", toujours au nom de la sacralisation des dictionnaires et des atlas. Dans son Lexique roman Raynouard (1844, tome IV : p. 402) traduit ainsi palliure par « ronce»: or, aucune confusion n'est commise par les natifs entre le paliure et la ronce, car elle est impossible, même si les deux végétaux ont un point commun, celui d'être pourvus d'épines. Il en donne l'étymologie : «du latin paliurus, ronce ». Sur ce seul exemple on constate tous les manquements possibles à la botanique et les errements de la compilation. En effet, l'auteur du dictionnaire de latin Gaffiot donne «paliurus, f., paliure (sorte de ronce) », avec référence erronée à la ronce, le Paliure étant un arbuste de 3,50 $\mathrm{m}$ de haut et certes pas une liane. Ensuite Raynouard censure volontairement paliure (?), ne recopie que la deuxième partie de la traduction, et encore en enlevant le « sorte de... », affirmant ainsi que c'est une ronce. On passe d'une approximation déjà fort gênante chez Gaffiot à une erreur totale de Raynouard qui, ne connaissant visiblement pas le mot et l'objet paliure, s'est autorisé à faire des raccourcis dommageables.

Plus étonnantes sont les erreurs de traduction commises par l'auteur lui-même. Ainsi Max Rouquette (2020: 76), auteur ancré dans son territoire pourtant, qui, de son vers évoquant les salades sauvages "Renèbre, tèrragrèpia e tu, lachuscla», donne comme version française "Sanguisorbe, scorsonère et toi laiteron", trois traductions fausses. Outre que la plume lui a fourché en donnant lachuscla (nom des euphorbes, toutes toxiques) en place de lachuga (laitue), la traduction souhaitée est « Oseille, terregrèpe et toi, laitue / laiteron ». Ces fausses équivalences ont été pourtant reprises et enregistrées comme telles sur un site consacré au lexique du parler de Montpellier.

Donnons encore un exemple récurrent d'erreur à propos du vocable giroflada, trop systématiquement traduit par giroflée, par attraction sur le français. Pourtant F. Mistral restitue bien la bonne traduction qui ne concerne que des œillets et les auteurs anciens ne s'y trompaient point. Mais si nos œillets s'appellent giroflada, c'est que, comme la giroflée (violier ou garanier en occitan, selon les espèces), ils sentent le clou de girofle. Bien des traducteurs de textes occitans du xix siècle, et a fortiori bien des lexiques contemporains de l'occitan s'obstinent pourtant à établir l'équivalence diglossique giroflada = giroflée, qui ne fait que contaminer de futurs écriveurs. On subodore le 
comportement de nos traducteurs : giroflada « sent » tellement la giroflée en français, qu'il est parfaitement inutile d'ouvrir le dictionnaire de F. Mistral pour vérifier une évidence. Eussent-ils ouvert aussi la flore de Coste, qu'ils auraient vu l'explication du nom de la famille botanique des œillets, les Caryophyllacées, formé sur caryophyllon, nom du clou de girofle en grec. "Quand on ne sait rien des choses de la nature dans sa propre culture, [...], on ne peut guère espérer s'y retrouver dans la connaissance naturaliste des autres et le savoir-faire où il se manifeste...", disait encore Jacques Barrau (1983, p. 5-12).

\section{Quelques phytonymes occitans}

L'analyse d'un corpus de quelques milliers de noms occitans relevés pour 1600 plantes environ fait apparaitre ce que nous appellerons des statuts lexicaux bien différents : abondance, voire surabondance, de noms pour certains végétaux, économie pour d'autres. Si l'abondance est un atout pour accéder à l'imaginaire d'un groupe humain, le théoriser, et le comparer à d'autres groupes d'un autre dialecte ou d'autres langues, c'est un inconvénient lorsqu'il s'agit de transmettre en formation, en sorties botaniques ou en conférences car, par définition, le public y est très divers. Les nombreuses sorties botaniques que nous encadrons nous permettent de confirmer ou élargir des localisations lues dans les dictionnaires ou les atlas.

\subsection{Plantes faisant la quasi-unanimité lexicale}

Nous allons détailler les noms dialectaux de quelques végétaux, en nous en tenant aux dialectes provençal (p.) et languedocien (l.), précisés éventuellement par le numéro du département et l'emplacement ( $\mathrm{O}$, ouest, $\mathrm{N}$, nord, etc.) ou mar. (maritime), mars. (marseillais), rhod. (rhodanien). Précisons que, comme pour les dictionnaires de Vayssier (1876), de Mistral, les localisations données sont informatives mais non restrictives. Elles sont issues des atlas, de nos enquêtes de terrain, et des témoignages écrits relevés chez des auteurs fiables géographiquement parlant, c'est-à-dire ceux dont on sait qu'ils employaient / emploient le parler de leur lieu. Il y a certainement des variantes qui n'ont pas été relevées (et sont-elles encore relevables?), obéissant aux traditionnelles mutations (e/a, e/i, l/r, b/v, r/d), chutes de consonnes intervocaliques, diphtongaison (o/oè, o/oa, iu/ieu), métathèses, vocalisation/ palatalisation, etc., que nous ne détaillerons pas, pas plus que la réalisation de ces noms à l'oral.

\subsubsection{Les grands arbres}

Pour la plupart ils sont tous nommés en latin (sauf les introductions plus récentes à partir $d u \mathrm{xVI}^{\mathrm{e}}$ siècle bien sûr où ce sont les botanistes qui les nomment artificiellement), ils présentent une unanimité d'appellations, aux variations dialectales près à partir d'un même étymon. L'ALLOR, l'ALP, les auteurs, nos enquêtes, les toponymes, montrent que le Chêne vert (Quercus ilex) oscille entre elze n.m. (l.:30N, 48S, 07), euse n.m. (1.:34, $30 ;$ p.: 13, 84), euve n.m. (p. mar.: 13, 83), var. eve (p.: 04), eusin n.m. (l.: $34 ;$ p.:13), eusina n.f. (l.:11; p.:13, 84), var. ausin, ausina n.f. (l.:11), tous issus du latin ilex. Un plus curieux tosca n.f. est donné pour le Var, et dans des textes d'auteurs du XIXe , terme générique signifiant touffe, cépée. Mais certains géants 
pluricentenaires épargnés par la cognée et le feu viennent rappeler qu'il peut être gigantesque. On notera que ilex le renvoie au grand houx (Ilex aquifolium) par ses feuilles parfois hérissées, lorsqu'elles sont jeunes. Le français l'a emprunté à l'occitan sous le nom de Yeuse.

Le chêne blanc méditerranéen (Quercus humilis) ne connaît que rore n.m. (l.) (variantes roire, roeire, 1.), rove n.m. (1.:12, p.), du latin robur. La forme garric n.m. (1.: 81, 11, 34) apparaissant dans ALLOR (carte $\mathrm{n}^{\circ} 248$ ) ou les textes d'auteurs semble avoir un statut qui a évolué. A-t-elle concernée au départ Quercus robur (ex pedunculata) et Quercus petraea (ex sessiliflora), absents des garrigues méditerranéennes? Nous ne saurions trancher, mais il est certain que ce vocable de garric est employé maintenant par des auteurs contemporains dans des territoires où aucun auteur ancien ne l'employait auparavant (dans la zone de Montpellier par exemple) et où nous ne l'avons pas non plus relevé sur le terrain. Il semble même fonctionner comme terme générique pour "chêne ", peut-être chez des auteurs ayant perdu la connaissance de la distinction claire euse / rore. Garric est construit sur la racine pré-indo-européenne garr-, signifiant rocher, tous nos chênes étant systématiquement rattachés à un sol rocheux. On la retrouve bien sûr dans garrigue désignant l'association végétale dégradée des terres méditerranéennes et dans les noms du petit chêne épineux et rabougri, garrus, agarrus, le chêne-kermès évoqué ci-dessous, arbre des rochers par excellence.

Parmi les arbres peu sujets à variabilité, on citera encore le chêne-liège (Quercus suber) cantonné aux terres acides qui se nomme suvier n.m. (p.) ou siurièr n.m. (l.), du latin suber. Les frênes (Fraxinus sp) ne varient que de fraisse n.m. (l., p.) à frais n.m. (p.), du latin fraxinus. Pour les peupliers, on distingue clairement auba n.f. (p.) ou alba n.f. (l.), aubar n.m. (l.), aubera n.f. (p. : 84) pour le peuplier blanc (Populus alba), de pibola n.f. (p.), piva n.f. (p.), pibol / pibol n.m. (1.:34), pigol n.m. (l.:11S), pive n.m. (1.:30C) et toutes leurs variantes pour le peuplier noir (Populus nigra). Plus rarement, on trouve aussi la différenciation lexicale entre les deux espèces sous la forme pibol / pibol blanc (1.:11, 34), pibola / pibola blanca (1.: 30), tout aussi pertinente. Une présentation erronée façon atlas ne consacrerait qu'une seule et même carte à « Le peuplier » et noterait donc ces appellations bien différentes toutes regroupées, concernant des taxons bien différenciés populairement. Une lecture hâtive mènerait à la conclusion que «LE peuplier connaît une variabilité d'auba à pibola ».

L'ALLOR donne bien une carte pour Populus nigra, tout en indiquant à part les noms du Peuplier blanc. Mais la phrase de présentation montre l'éternelle erreur d'approche du sujet (carte $\mathrm{n}^{\circ} 252$ ): "Les mots de la carte sont des termes génériques qui, sauf indication contraire, s'appliquent à l'ensemble des arbres du genre Populus.» On retrouve l'application ethnocentrique d'une grille de lecture d'une langue (ici la notion de genre botanique en français de botanistes) aux savoirs populaires d'une autre langue, ici l'occitan, où la notion de genre est justement peu commune. On ne fera jamais dire pibola à quelqu'un qui nomme auba le Peuplier blanc.

Les Occitans cueillent plusieurs salades sauvages du genre Crepis, certes pas vécues comme appartenant au même genre, mais ils les reconnaissent sans faille, au contraire de bon nombre de botanistes. Il faut admettre comme préalables incontournables les grilles de lecture des autres (pas moins opératoires, pas moins pertinentes, puisqu'elles ne poursuivent pas les mêmes buts) lorsque l'on prétend enquêter sur leurs savoirs, et non appliquer ses propres grilles qui induisent dès le départ à poser des questions erronées dans leur formulation, comme la carte «Chêne» de l'ALF ou celle 
«Le genévrier» de l'ALP vues ci-dessus, suivies d'absence d'analyse critique des réponses obtenues.

Variation encore plus réduite pour le pommier et les arbres fruitiers en général : pomièr n.m. (l.) et pomier n.m. (p.), avec toutefois la forme pomièira n.f. (l.) / pomiera n.f. (p.), lorsque l'arbre est chargé de fruits. Mais nous avons mis beaucoup de temps à comprendre cette subtilité grammaticale et sémantique (mal expliquée chez Mistral qui se contente d'un "arbre qui porte des pommes", ce qui semble évident pour un pommier). Être chargé de fruits renvoie à l'image même de la fécondité, renvoyant forcément au principe féminin. Bien d'autres arbres connaissent ce couple masculin/ féminin selon leur état végétatif : prunièr / prunier, castanhièr / castanhier en général, mais prunièira / pruniera, castanhièira / castanhiera (chargées de fruits). Si on arrive à le retrouver dans quelques écrits anciens, ce distinguo s'est quasiment perdu et nous œuvrons pour le réactiver dans nos enseignements, tellement il est riche de sens. Lorsque nous l'évoquons en sorties botaniques, quelques rares informateurs nous l'ont confirmé (en Languedoc), mais ils l'avaient le plus souvent effacé de leur mémoire, car ils n'avaient " pas compris la distinction que faisait mon grand-père ».

Le figuier présente le même doublon figuièr / figuièira (l.), figuier / figuiera (p.), mais nous n'avons pas réussi à comprendre si cela correspond systématiquement à figuier mâle au masculin (caprifiguier) à figues non comestibles vs figuier femelle au féminin à figues comestibles. Ce que l'on pourrait croire à partir du seul exemple de figuier au masculin donné par Mistral dans son dictionnaire: "figuié fèr, figuié cabrau, caprifiguier " (p.1132), qui sert à féconder les figuiers femelles, puisque l'arbre est dioïque. L'ALLOR (carte ${ }^{\circ}{ }^{2} 288$ ) restitue toutefois une autre distinction: dans certains lieux du Gard, figuièr désignerait un arbre isolé, tandis que figuièra nommerait une touffe de plusieurs troncs (augmentatif féminin logique). Le platane connaît majoritairement la forme féminine la platana (l., p.), en toute logique par rapport à l'étymon latin (rappelons que tous les noms d'arbres latins en -us sont les exceptions féminines de la deuxième déclinaison), mais aussi masculine lo platanièr (l. : 11). Là non plus, nous ne comprenons pas pourquoi, ses fruits n'étant pas du tout comestibles. Il reste donc encore bien des enquêtes à mener pour démêler des écheveaux grammaticaux et sémantiques liés, malheureusement de plus en plus difficiles à envisager avec la disparition des détenteurs de ces savoirs. 
Figure 8. - Poirier en fleurs (Pyrus communis) - Un Perier (p.), un Perièr (I.).

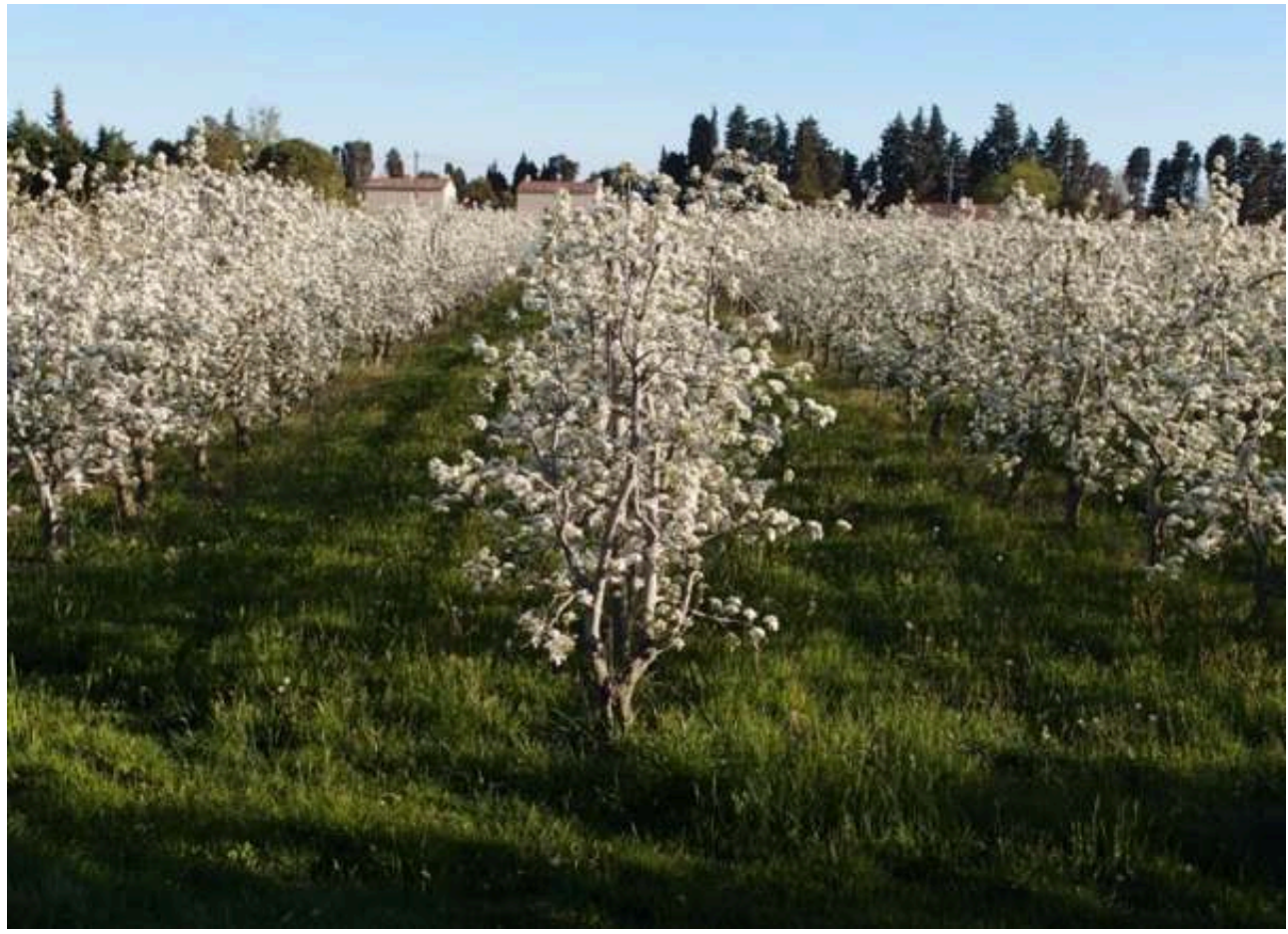

Photo : Josiane Ubaud.

Figure 9. - Poirier en fruits (Pyrus communis) - Una Periera (p.), una Perièira (l.).

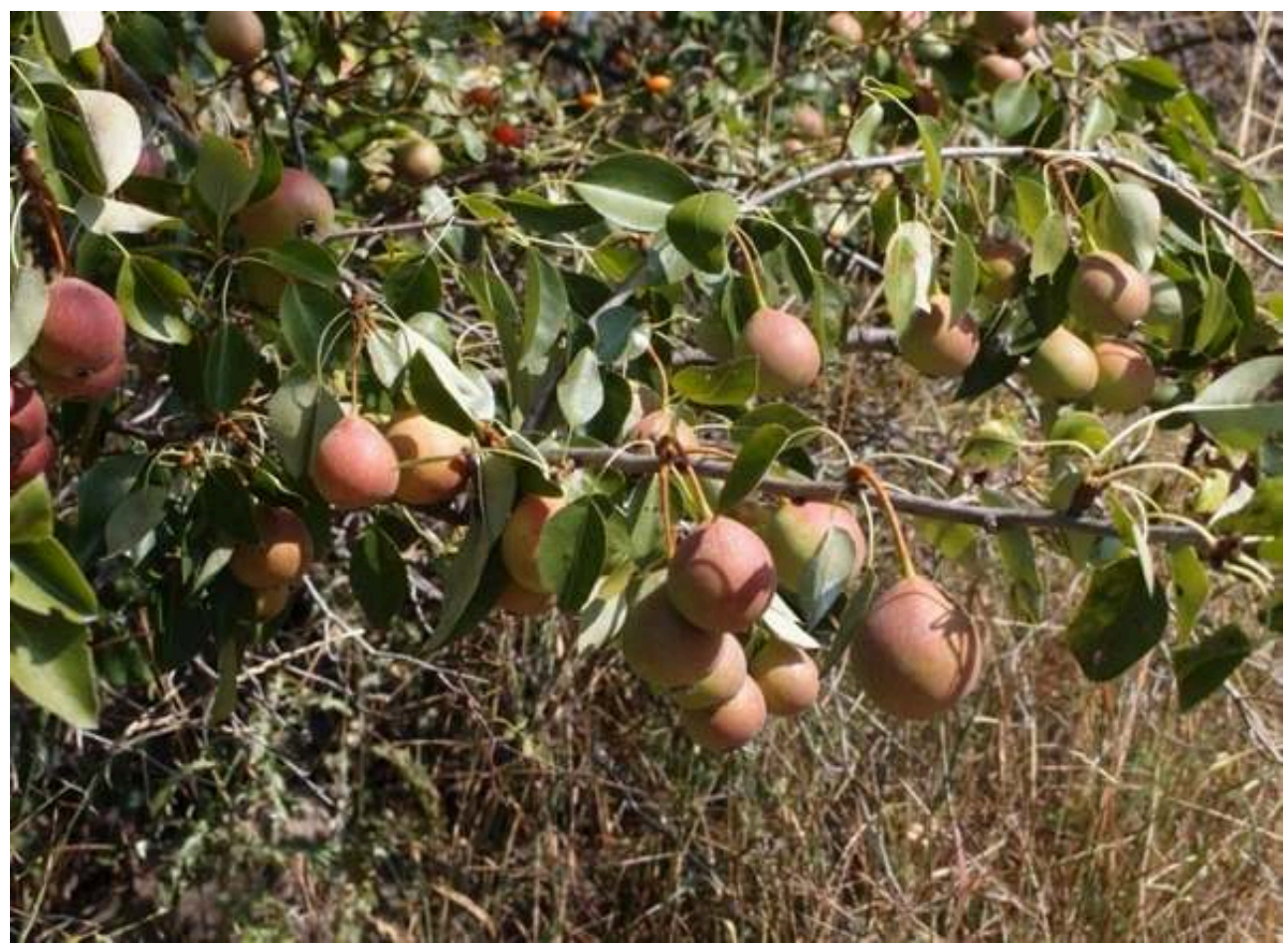

Photo : Josiane Ubaud. 


\subsubsection{Les exceptions notoires du micocoulier et du chêne-kermès}

Un seul grand arbre vient notoirement se différencier face à cette quasi-unanimité lexicale autour d'un seul étymon, c'est le Micocoulier, seul dans son genre en terres occitanes. Le Celtis australis (le Celte du Sud, car vénéré par la tribu des Celtes arécomiques, capitale Nîmes) connaît une profusion de noms, paradoxale pour un grand végétal. Un de ses noms occitans est bien plus parlant sur le plan de sa sacralité : fanabrégol, fanabreguièr, formé sur le latin fanum, le temple, et le gaulois brogilon, le bois, la forêt. C'était l'arbre sacré des Celtes arécomiques, et le sens motivé est perdu. Ce vocable connaît déjà en lui-même bien des variantes que l'on peut relever chez Mistral ou dans les atlas, car pour ce cas il n'y a pas d'approximations possibles, il n'y a bien qu'un seul micocoulier dont tous les vocables sont masculins : (ALLOR, carte $\mathrm{n}^{\circ} 262$, ALP) fanabrégol (l. : $34[\mathrm{C}, \mathrm{N}], 30 \mathrm{C})$, fanabreguièr (l), fenabreguièr (l.), fanagrévol (l. : 30N), falabreguier (p.), farabreguier (p. mars.: 13), falabriguier (p. mar.: 13), farabregorier (p.:83), fanfaligolier (p. rhod.: 13), fabreguier (p.), fabrigoron (p.), fabrecorier / fabregolie (p.), fabrigorier / fabrigolie (p.), fabrecolier (p.:06), brigolier / brigorier (p), et certainement d'autres. Mais il connaît aussi les vocables micocolièr $(1 .: 30,34,11)$ et variantes micacolièr (1. : 340), milicoquièr / melicoquièr (1. : 30), aubre de micacolas (1. : 34S), qui sembleraient dériver du grec microkoukouli, fruit minuscule. Et encore la série belicoquièr / belicoquier (1.:30), et ses multiples variantes balicoquièr, baricoquièr, bricoquièr, bericoquier (1. : 30), aubre de belicòcas (1. : 30S), vocables dus selon Mistral, à ses petits fruits non mûrs couleur d'abricot, < latin praecocum >, arabe al barkouk, ou en forme de perles couleurs de miel, < latin melichrota >, bricacolièr (1.). Et encore picapolier (l.: 30S), (a)fatolier (l.: 30NE), forquièr (1.: 30, Sauve), bataculier (p. : 83), flaguier (p.: 83), paparotier (p. : 84), sentís / centís ? (p. : 06), petolier (p), fresicolier, petier / petièr. 
Figure 10. - Micocoulier (Celtis australis) - Fanabrégol, Fanabreguier, Falabreguier, Micacolièr.

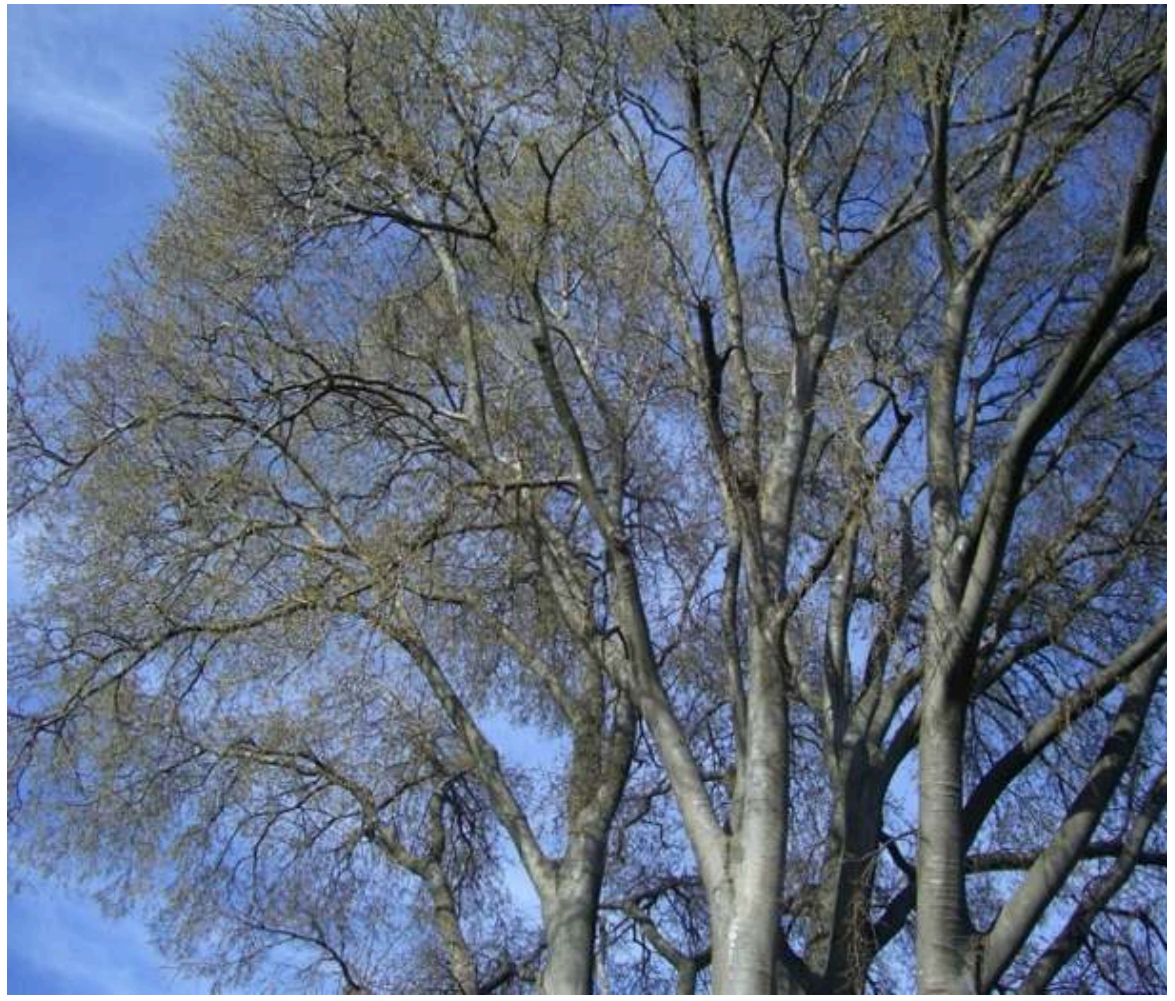

Photo : Josiane Ubaud.

Figure 11. - Micocoules en forme de crottes - Micacolas, Falabregas.

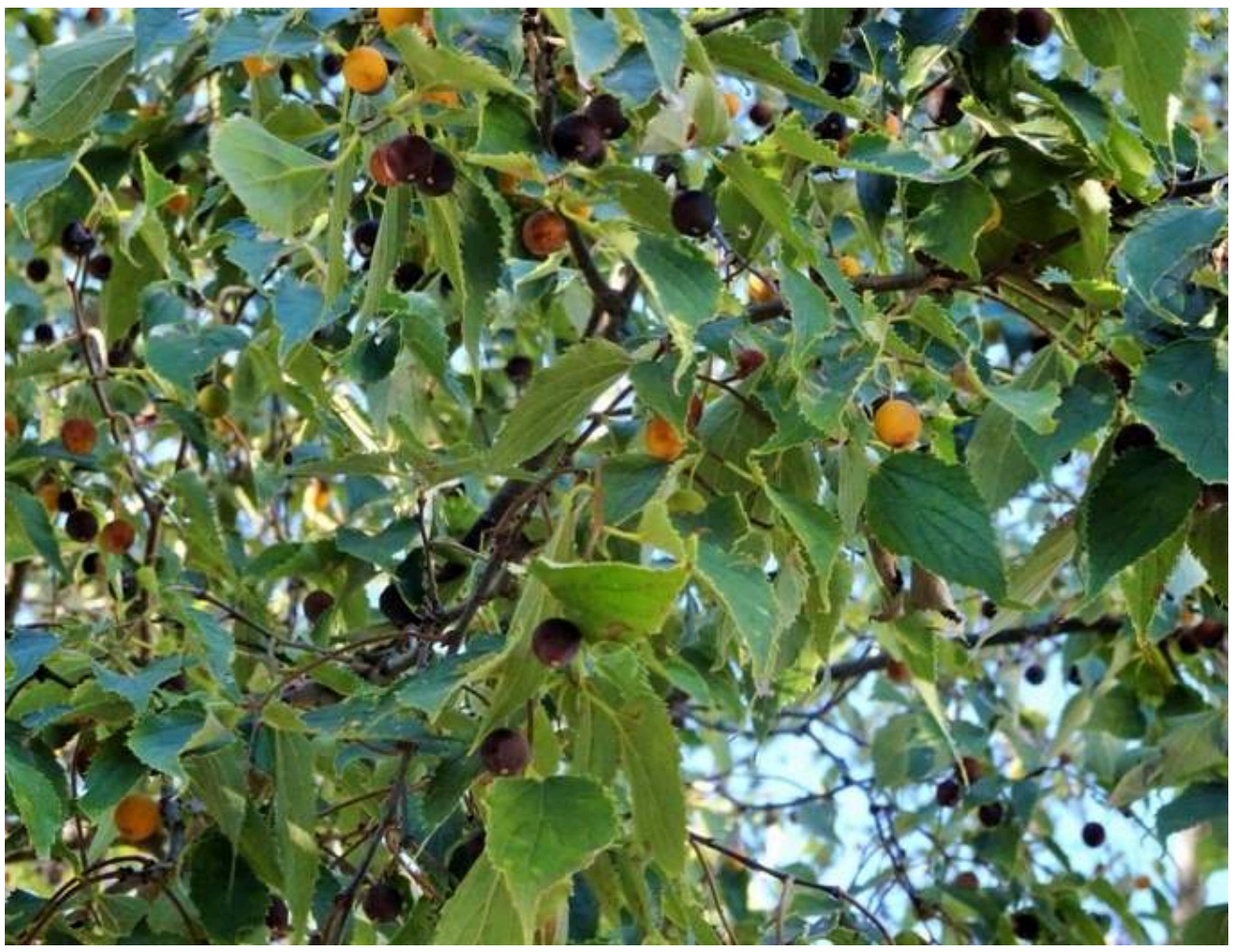

Photo : Josiane Ubaud. 
elier / petier renvoient à la forme de ses fruits minuscules et noirs comme des crottes (peta, petola) ce que chacun peut constater, picapolier au fait que ses fruits font le délice des poules (tout comme le cépage héraultais picapol), forquièr parce que l'on fabrique des fourches (forca) à trois branches avec ses jeunes sujets à Sauve (30), bien des noms sont a priori obscurs et demanderaient des enquêtes approfondies, y compris les étymologies données par Mistral. À propos de petier, il faut signaler une autre source de confusion, récurrente dans le dictionnaire de Mistral qui donne : «petié, petiè (l.), s. m. Micocoulier, etc. ». D'où l'on serait tenté de conclure que petier serait une forme provençale, et petièr une forme languedocienne. Or rien n'est moins sûr puisque nous avons démontré en préface de notre dictionnaire orthographique (Ubaud, 2011) que Mistral a tantôt provençalisé des formes languedociennes, tantôt languedocianiser des formes provençales, et qu'il travestissait l'orthographe des auteurs non rhodaniens qu'ils citaient pour les faire rentrer de force dans le moule du provençal rhodanien. Nous en donnons des dizaines d'exemples. Les écrits de ces auteurs ne peuvent donc servir de preuves de géolocalisation d'une forme de lexique en général et d'un phytonyme en particulier. Il faut revenir aux textes originaux et non se contenter des citations restituées dans le Trésor du Félibrige. Pour cette entrée particulière, les deux formes existent-elles vraiment? Ou bien l'une est-elle la fille théorique, transformée autoritairement par Mistral de la forme mère?

Figure 12. - Chêne à kermès (Quercus coccifera) - Avaus, Agarrús, Garrolha, Gràubia, Eusilha.

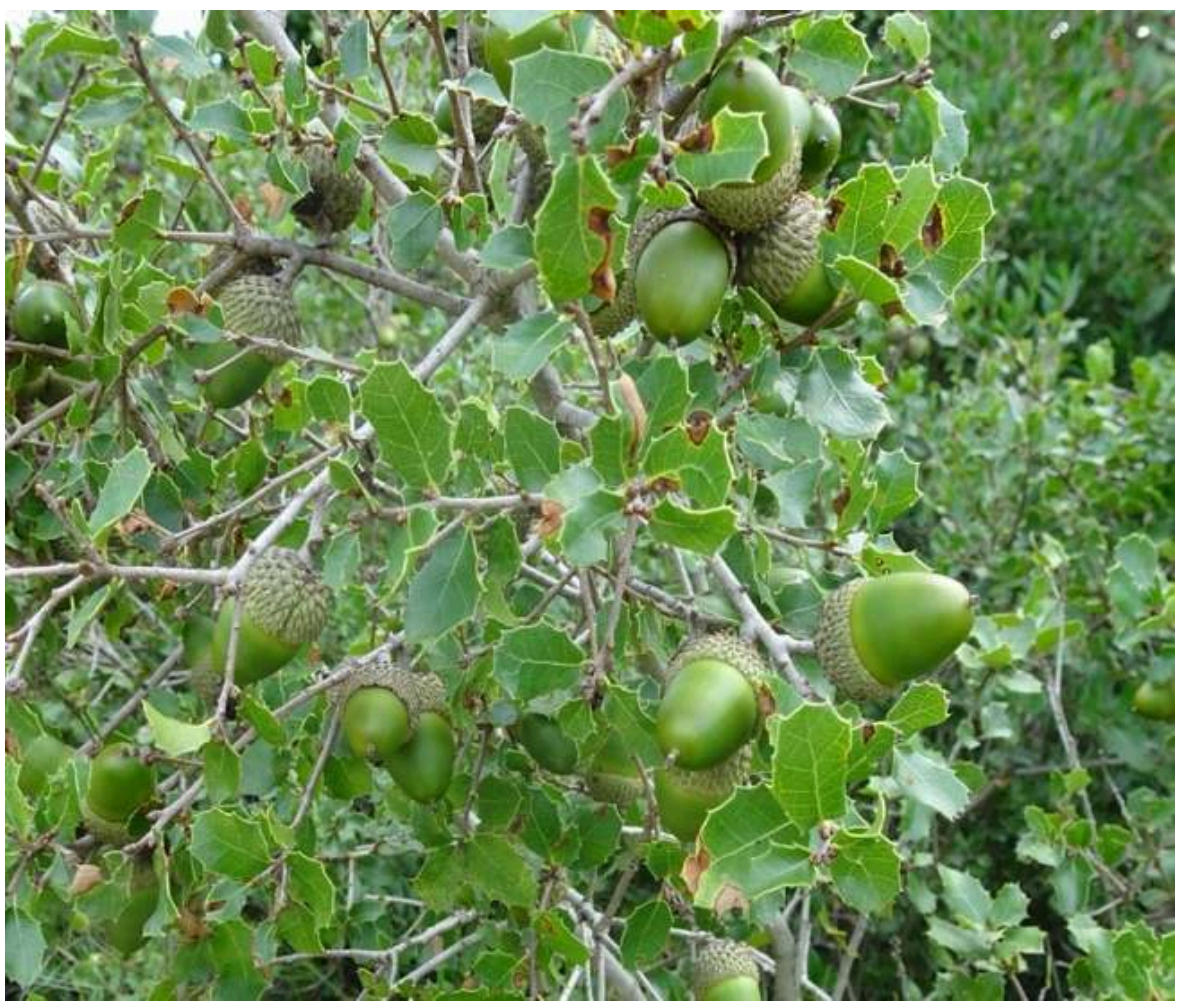

Photo : Josiane Ubaud.

Le Chêne à kermès ou Chêne-kermès est de taille bien plus modeste, mais il peut atteindre en réalité une hauteur bien plus importante (3-4 $\mathrm{m})$ que ce qu'il nous est donné à voir dans nos maigres garrigues, car il a été surexploité (ou éternellement incendié). Comment un arbrisseau aussi fréquent et aussi utilisé (galles tinctoriales 
réputées, tanins, combustibles) a-t-il pu se disperser ainsi lexicalement? On aurait attendu une plus grande unité. La série formée sur la racine garr- (pierre) déjà vue est logique, car c'est le chêne des rochers par excellence : garric n.m. (1. ? chez Mistral, douteux), (ALLOR) garric salvatge (1.:11SO) (salvatge est à prendre au sens de bâtard, chêne bâtard par rapport au "vrai » garric, Quercus robur par exemple), (ALLOR) garrolha n.f. (l.: 11, 340) (en fait nom du tan que l'on en tirait), (ALLOR, ALP, auteurs, enquêtes) garrús (l.) / agarrús n.m. (p. rhod.). Le vocable avaus n.m. (l. orient., p.) et ses variantes avals (l. : 34), agaus (l. : 300), n'a pas encore trouvé son explication.

Si en Languedoc il a été rattaché sémantiquement au garric, en Provence (ALP, auteurs, enquêtes) on le trouve associé au Chêne vert euse par le diminutif eusilha n.f. (p.: 84) : c'est en effet un petit Chêne vert en taille mais en plus piquant. Un nom mystérieux, gràubia n.f. en Cévennes (Mistral le rattache possiblement à garrabier, l'églantier, donc par comparaison avec son aspect épineux), deux noms motivés reganèu n.m. (p. : 83) « le rébarbatif " (qui n'a pas promené en garrigue avec les mollets en sang ne peut comprendre...), et petarèla n.f. (l. : 34SE) (enquêtes), car c'est un bois qui pétille très fort au feu, et il alimentait tous les fours domestiques. Curieusement, le fait qu'il porte la précieuse cochenille (le kermès, la grana, lo vermet) qui servait à teinter en rouge les draps de luxe et a fait la fortune de Montpellier, ne lui a point fourni un nom.

\subsubsection{Des plus petits végétaux aussi stables lexicalement que les arbres}

Des sous-ligneux ou des herbacées connaissent eux aussi une stabilité lexicale quasi générale, toujours aux variantes près traditionnelles. Les thyms - et non le thym, par contre tous très proches visuellement et assimilables populairement à un collectif au singulier - dérivent tous du latin fericula, petite plante sauvage : (d'après ALLOR, ALP, auteurs, enquêtes) ferigola n.f. (1.:30S; p.:13), frigola $(1 .: 82,11,34,30,07,30 \mathrm{~N}, 07$; p. : 13), farigola, faligora, farigora, faligola (p. mar.), faribola (l., 81), fribola (1., 81, 12, 11), fornigola (1.:34), friol n.m. (1.:12), friola (1.:12, 34), farugra (p.: 83), faligra (p.: 83), et certainement d'autres variantes. Une exception étonnante toutefois pour pòta n.f. $(1 .: 34,30)$, appellation spécifique de la zone de Montpellier-Ganges et plus vers l'est, jusqu'à Clarensac et Saint-Hippolyte-du-Fort pour le Gard. Mistral rattache le vocable à pòta, lèvre. Effectivement les thyms sont des Labiées (donc ayant des fleurs en forme de lèvres), mais cette observation de si près sur une fleur si petite a de quoi surprendre. Honnorat (1845) donnait antérieurement à Mistral une autre explication : ce serait une plante qu'on porte aux lèvres. On se gardera donc de conclure quoi que ce soit. Ces îlots lexicaux nous étonneront toujours, autant par le phytonyme totalement isolé dans une aire majoritairement vouée à ferigola, que par son aire d'usage dont on cherche une explication au contour. Quant au serpolet, s'il est bien un Thymus botaniquement parlant, il est nommé individuellement et très majoritairement serpol, serpolet (nom latin botanique Thymus serpyllum, qui reprend le nom de la plante chez les Latins, serpyllum ou serpullum).

La Sauge officinale (Salvia officinalis) est unanimement identifiée sous son nom de sàlvia n.f. (l.) / sàuvia (p.), de son nom latin salvia, celle qui sauve. Le Romarin (Rosmarinus officinalis) est stable, car il dérive lui aussi de son nom en latin rosmarinus: (d'après ALLOR, ALP, auteurs, enquêtes) romanin n.m. (l.:11, 34, 12, 30, 07 ; p.: 13, 84), romanís $(1 .: 34,30)$, romarin $(1 .: 11,12,30)$, aromarin $(1 .: 12)$, romanieu $($ p.:13, 84), rosmarin (p.:06). Le Fenouil commun (Foeniculum vulgare) est encore plus stable: fenolh n.m. (1.:11, 12, 34, 30; p.:13, 84), fenon n.m. (1.:30, p.rhod.), du latin foeniculum. Le 
Pistachier lentisque (Pistacia lentiscus) connaît toutes les variations évoquées plus haut à partir de ses noms latins lentiscus ou lentiscum: (ALLOR, ALP, auteurs, enquêtes) lentisque n.m. (1.:34), lentiscle (p.), lantiscle (p.), lenchiscle (pour lengiscle ?) (p. mars.), lentisclièr (1.:34), restincle, restingle, rastingle, rastincle (1.:34), rastencle, restencle (l. orient, p. rhod.), gentiscle (1.:11S, 340). Nous avons relevé le nom motivé coiratàs à Cabrières (34) (donné aussi par l'ALLOR), sans doute dû au fait qu'on l'a utilisé dans les tanneries pour traiter ou teinter les cuirs. Et on note encore un mystérieux tois n.m. (l. : 34NO) qui a priori nous renvoie plutôt vers le nom de l'If (Taxus baccata, tueis en provençal) ou un nom générique pour touffe, buisson. Notons que pour ce cas, l'ALLOR commet encore la faute de baptiser sa carte $n^{\circ} 224$ "Pistachier» au singulier, mais donne plus rigoureusement les noms du Pistachier térébinthe et du Pistachier lentisque séparés par un point-virgule, et ne se livre point à donner des dominantes d'aires comme il le fait pour la carte «Plantain" ( $\left.n^{\circ} 162\right)$. Là aussi on peut s'étonner de ces deux traitements différenciés au sein d'un même ouvrage, l'un faux, l'autre exact.

Figure 13. - Pistachier lentisque (Pistacia lentiscus) - Lentiscle (p.), Restincle (l.).

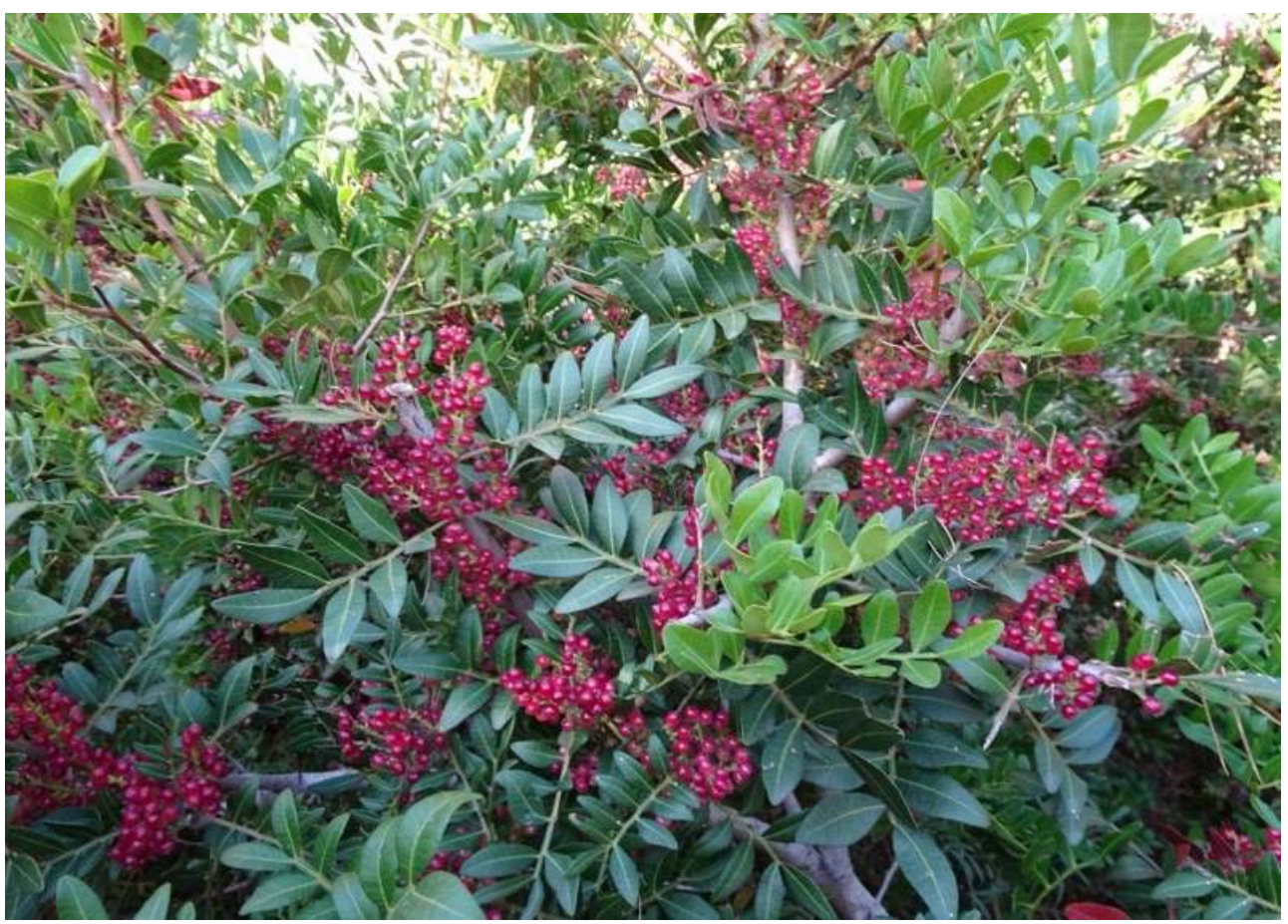

Photo : Josiane Ubaud. 
Figure 14. - Carte «Pistachier » de l'ALLOR (carte $\left.\mathrm{n}^{\circ} 224\right)$.

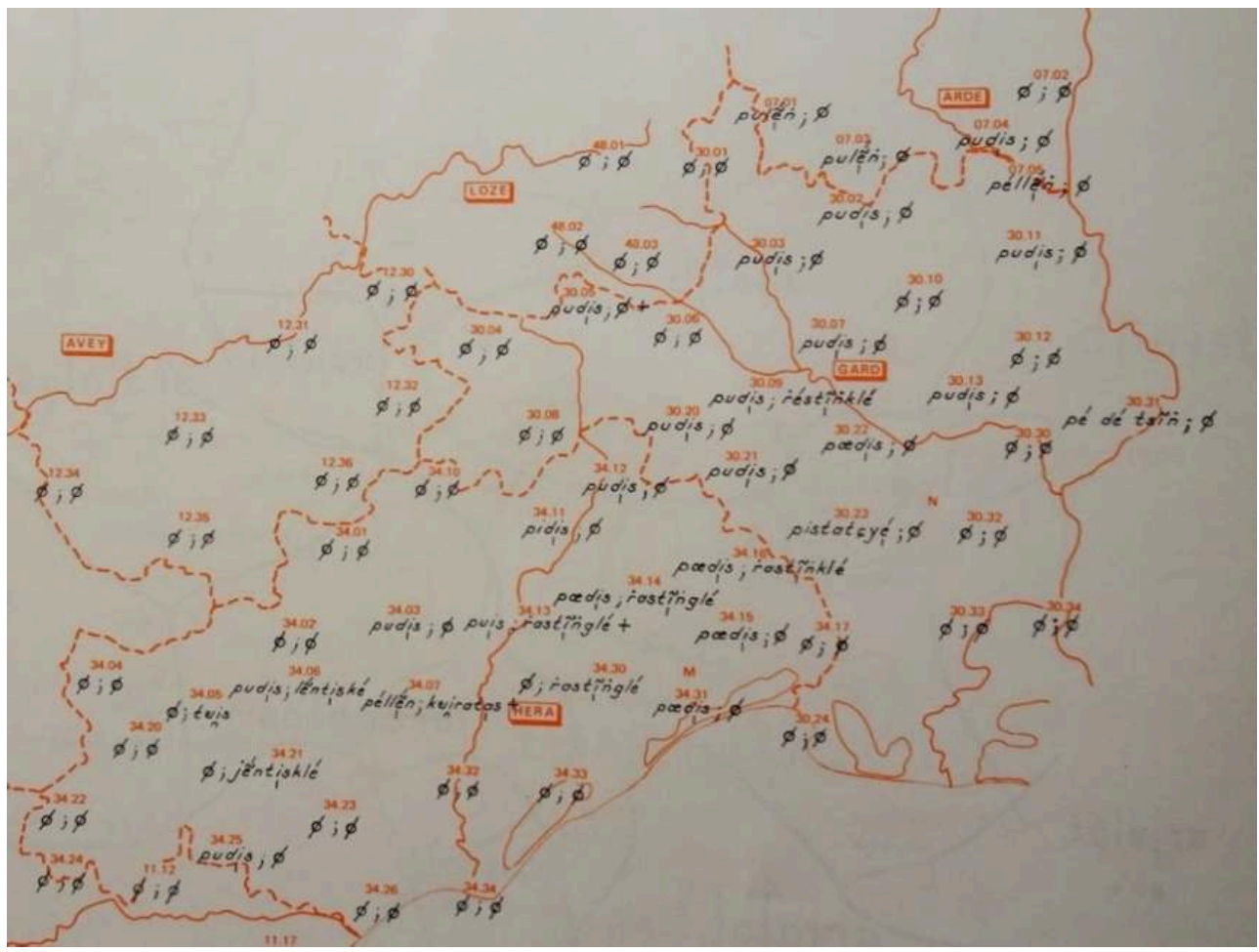

J. Boisgontier (1981-1986), Atlas linguistique et ethnographique du Languedoc oriental (ALLOr).

À rebours, reste une énigme pour le vocable badassa (et variantes baiassa, badafla) qui désigne au contraire une multiplicité de plantes les plus différentes qui soient : thyms, lavandes, cistes, Dorycnium pentaphyllum, Plantain des chiens (Plantago cynops), Plantain des sables (Plantago arenaria), Plantain pucier (Plantago psyllium), Cupulaire fétide (ancien nom pour Inula graveolens). Si certaines partagent le fait de présenter un port arrondi en touffes basses et d'être des sous-ligneux, ce n'est pas le cas du Plantain des sables (herbacée annuelle), du Plantain pucier (herbacée annuelle), de l'Inule fétide (port érigé). Quant à l'explication donnée par Mistral «plantes ainsi nommées à cause de leurs fleurs labiées qui badent » (p. 205), elle nous laisse plus que perplexe puisque seuls thyms et lavandes sont des Labiées dans cette longue liste comprenant des représentants de la famille des Cistacées, Fabacées, Plantaginacées, Astéracées. À noter que la forme francisée badasse s'est fixée essentiellement voire exclusivement sur le Dorycnium : elle est ainsi nommée sur bien des sites en français qui, pour une fois, ont pratiqué l'emprunt à l'occitan. Sans contexte descriptif (couleur, odeur, usages), cette polysémie rend bien difficile la traduction d'un texte occitan, car il faudrait connaitre la plante exacte associée au vocable badassa sur le territoire de l'auteur.

\subsection{Noms motivés multiples pour une même plante}

Plus on descend dans la taille du végétal, plus la surabondance du lexique est notoire pour des plantes communes pourtant. Nous ne parlons pas de variantes dialectales d'un même vocable vues pour les exemples précédents mais bien de noms bien différents affectés à une plante. Ils sont généralement très clairs de sens et disent une caractéristique de la plante : forme de la feuille, de la tige, présence de piquants ou de poils, couleur, biotope, usages communs, chaque regard pouvant déceler en priorité tel 
ou tel caractère. Nous allons détailler trois exemples de cette surabondance, sans mentionner toutefois les noms parfois utilisés uniquement au pluriel, qui est une caractéristique de la langue parlée populaire, et pas seulement en occitan : ainsi « c'est des coquelicots ", «c'est des marguerites » s'entendent fréquemment même si on ne montre qu'un seul pied.

\subsubsection{La Salsepareille}

51 La Salsepareille (Smilax aspera) est un exemple notoire de la multiplicité lexicale, rendant bien difficile un enseignement à un public hétérogène. Cette liane commune des garrigues, redoutable par ses épines, son potentiel de croissance et d'étouffement des végétaux qu'elle enlace, est négativement connue de tous, agriculteurs comme propriétaires de jardins, ce qui rejaillit forcément sur les appellations, pas toujours localisées dans les dictionnaires ou illustrées par une citation d'auteurs. Sa fonction de barrière redoutable et impénétrable comme un grillage (elle a même pu être plantée volontairement autour de jardins potagers) lui vaut son nom de riège n.m. (p.:13) (grillage et riejar, ariejar, grillager) et variantes ariège / ariuège n.m. (l. : 30), clarièja n.f. (l. : 11, 34), clariège / esclariège n.m. (1.), sacriège n.m. (1. : 34), sagrièja n.f. (1. : 30) (ALLOR, ALP, auteurs, enquêtes). Elle aurait donné son nom au Bois des Rièges au milieu de l'étang de Vaccarès en Camargue. Nous ne saurions classer la multitude de ses autres noms de sonorités voisines (qui est variante de qui ?) : esclaviège n.m. (l. : 34), escaliège n.m. (l. : 34), escalège / scalège n.m. (1. : 30, 34), saliège n.m. (l. : 34).

Son pouvoir agrippeur et déchireur de vêtements lui a valu les noms estacapaures n.m. (1.: 34), gratapaure n.m. (attache ou gratte-pauvre, ceux qui hantaient les garrigues), arrapaòme n.m., gripaòme n.m. (accroche-homme), arrapamans n.m. (l. : 30) (accrochemains, qu'elle partage avec la garance, ou confusion de l'enquête ?). Ou plus violent dans l'agression : estripacats n.m. (1.: 30), estranglacats (1. : 30) (étripe ou étrangle-chats). Elle gratte (gratar) voire scie (ressar) les membres de ceux qui s'y hasardent : grata n.f. (1.: 30, 07), peut-être grataquieu n.m. (1.:30, 07) (ou confusion avec l'églantier ?), rèssa n.f. (l. : 07). Elle est hérissée de véritables clous : clavièira n.f. (1. : 34). Elle épouvante (esglariar, effrayer, effarer) ceux qui s'y frottent : esglariat / aglariat n.m. (p.), variantes esclariat, eiglaiat, scaliat n.m. (p. : 83). Dans un jardin, elle est aussi invasive et impossible à extirper que du chiendent: gròs grame n.m.(p.), gros chiendent. Le vocable tiragassa n.f. (p. : 13) viendrait de tiragossar, houspiller, tirailler, tracasser, traîner, sens donnés par Émil Lévy (1909), qui correspond fort bien à la plante. La forme de sa fructification, en belles grappes rouges et luisantes la renvoie au raisin, mais un raisin " pour rien ", inutile, vierge, blanc (comme un chèque en blanc, ou un vent blanc, donc ne donnant pas de pluie) : rim vierge n.m. (p.), raï blanc n.m. (p.: 83) (variantes de rasim). Enfin un mystérieux siga n.f. (p.:06) est donné par Mistral pour la région de Nice, encore une fois à titre informatif et peut-être pas restrictif. 
Figure 15. - Salsepareille (Smilax aspera) - Fruits.

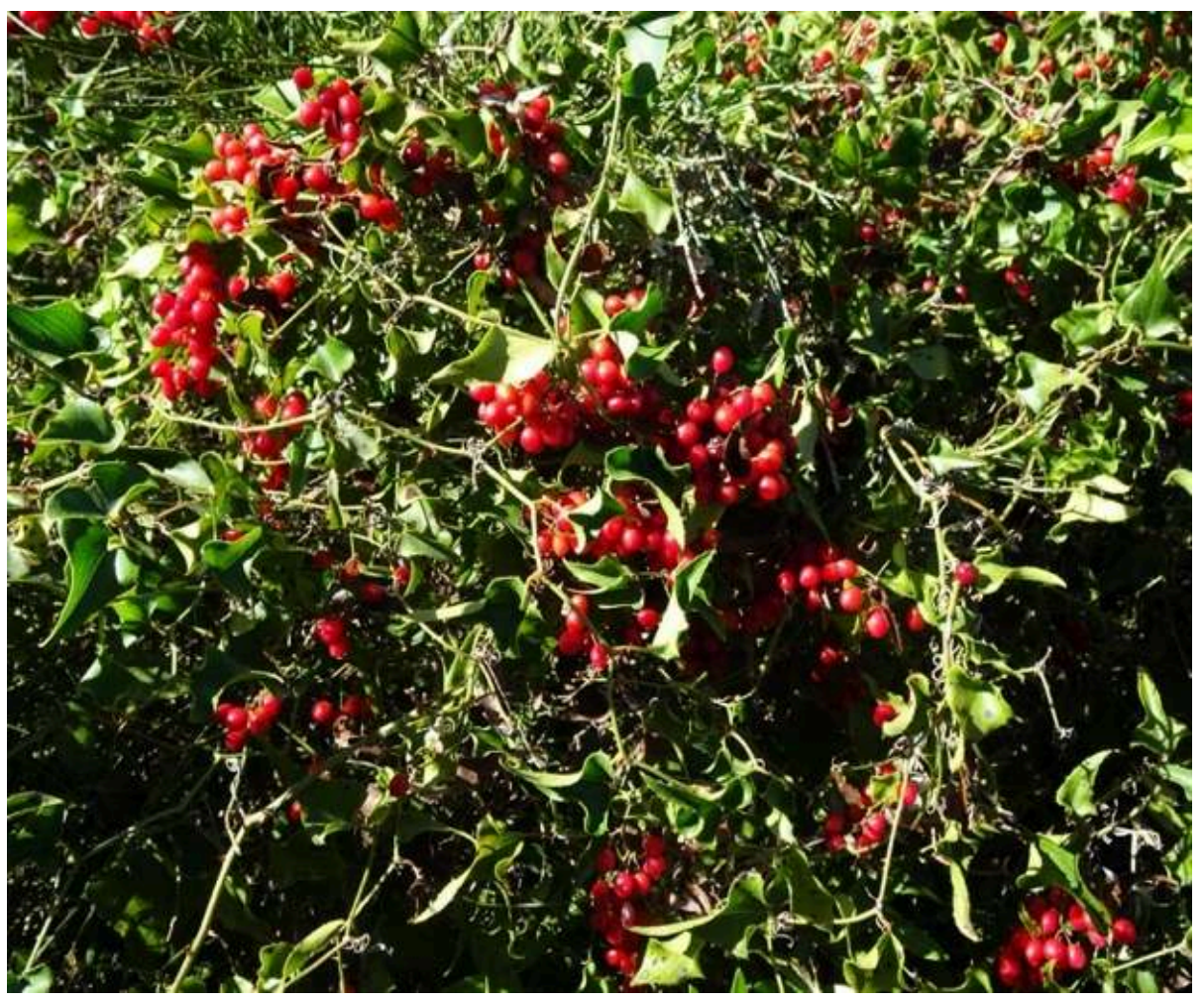

Photo : Josiane Ubaud.

Figure 16. - Salsepareille (Smilax aspera) - Fleurs.

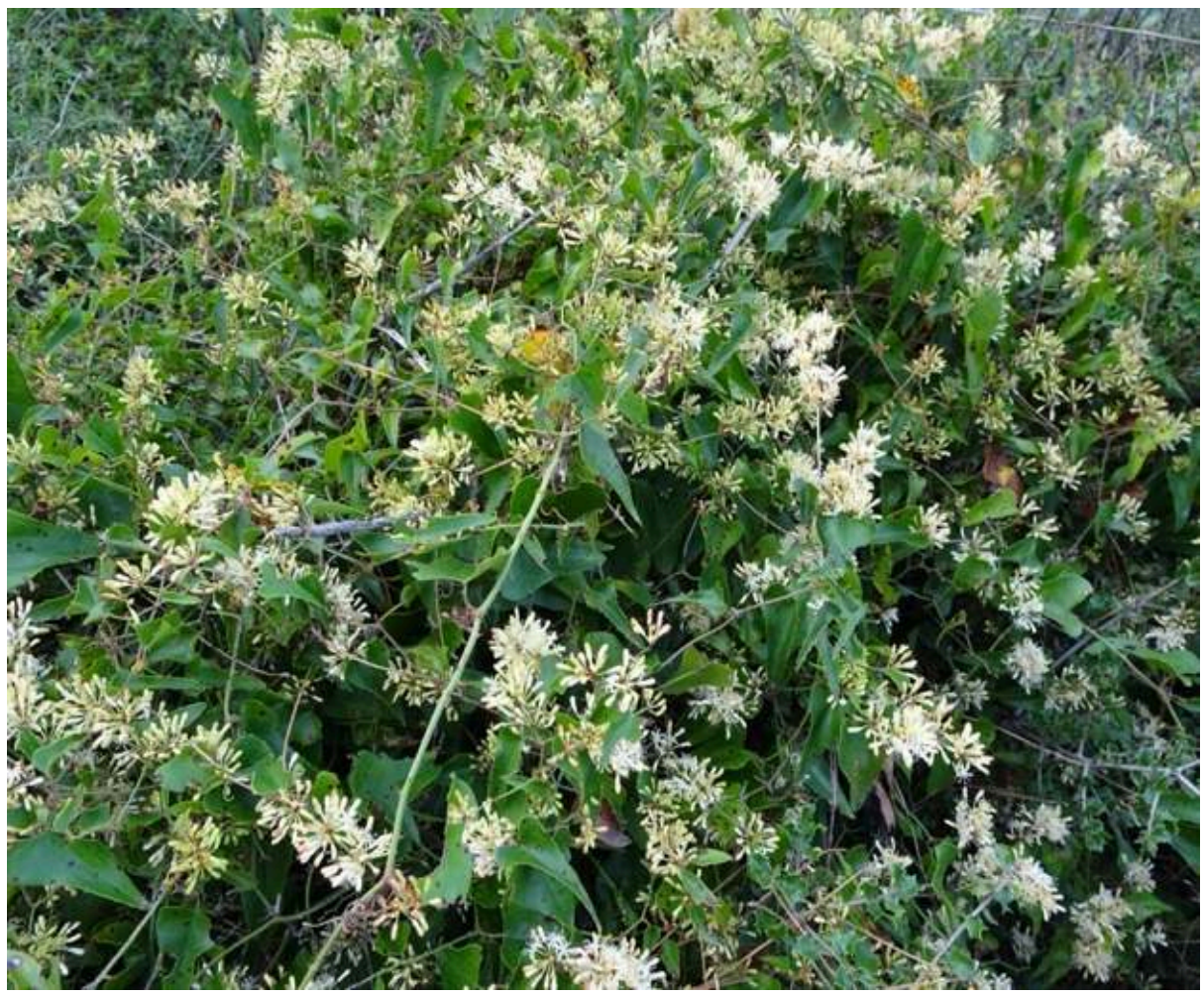

Photo : Josiane Ubaud. 
Et qu'en est-il de sarsaparilha donné par Mistral? Issu de l'espagnol zarza + parrilla, ronce + treille, le nom qualifie aussi très bien cette liane pouvant faire de véritables tonnelles entre les arbres qu'elle colonise. Elle est/serait venue d'Amérique du Sud - l'histoire précise des végétaux, tant leur origine que leur nom, est encore à écrire et arrivée en Espagne, d'où son étymon, qui a ensuite sauté les frontières. Pour les terres occitanes, en commençant par le Languedoc? C'est en tout cas sur cette même base que le portugais use de salsaparrilha, le catalan de sarsa, sarsaparella, l'italien de salsapariglia, et le français de salsepareille. L'ensemble lexical relève presque en entier du champ de la liane épineuse, envahissante et redoutable, et pourtant c'est aussi une plante médicinale précieuse, pour la circulation du sang, outre que ses jeunes pousses remplaçaient les asperges et que ses fleurs très parfumées donnent une liqueur des familles au goût caramélisé. Elle n'est donc pas que nuisible, mais le lexique ne lui rend pas cet hommage...

\subsubsection{La Clématite herbe aux gueux}

Cette clématite est fort commune dans les haies vives qu'elle enlace de ses longues tiges flexibles, comme une vigne, mais se couvrant de fleurs blanches, ce qui lui vaut son nom latin de Clematis vitalba. Elle a une sœur de garrigue Clematis flammula, toute aussi blanche de floraison, beaucoup moins volubile, avec laquelle elle n'est pas toujours distinguée nominativement. La carte $\mathrm{n}^{\circ} 194$ de l'ALLOR montre quelques aires majoritaires mais relativement petites et une multitude de noms descriptifs, donc point d'unanimité. Le nom de redòrta (34C, 300), redorton n.m. (1. : 07S), et ses variantes regòrta $(\mathrm{l} .: 12 \mathrm{~S}, 34 \mathrm{~N})$, areòrta $(\mathrm{l} .: 34 \mathrm{E})$, redòlta $(\mathrm{l} .: 34 \mathrm{~N}, 30 \mathrm{E}, 07 \mathrm{~S})$, rejòrta $(\mathrm{l} .: 07)$, ravòrta $(\mathrm{p} .:$ : 4$)$, rivòrta (p., mar.), est un terme générique signifiant lien végétal. Cette clématite très souple, comme l'osier, est souvent employée à cet effet : «redourta, attacher avec un lien d'osier " nous dit Mistral, limitant bien indûment l'usage à l'osier. Il en est de même pour vencilha n.f. (p.: 06) du latin vinculum, lien, attache. Dans le même champ lexical de la liane qui s'entortille, on trouve les noms de regortiòl n.m. (1.:12) (se regortilhar, s'entortiller), viradèla n.f. $(1 .: 11,340)$, variante vidarèla $(1 .: 340)$, viraula n.f. (l.) (de virar, tourner).

Deux autres familles de noms se distinguent en particulier : toute la série dérivée du latin vitalba, vidalba n.f. $(1 .: 66,11,34 \mathrm{~N}, 12 \mathrm{~S})$, vidauba n.f.(p.) et variantes vidalga (1. : 340), vidabla (1.), et même stricto sensu vinha blanca n.f., et des composants inversés albavitis, aubavit n.f. (1.:12, 30, p.: 83) et variantes aubrevit (1.:30), abravís, aubavís (p., mars.). Vigne blanche au sens de liane comme une vigne - elle peut échanger quelques noms avec la vigne sauvage - se couvrant de fleurs blanches, ou vigne sans intérêt car ne donnant pas de raisins, comme vu plus haut sur le sens de blanc?

Puis la série viçana n.f. (l.:340, 34S, 30N) (< viticeus +-anus) où l'on retrouve la référence à la vigne - hélas souvent orthographiée bissana même dans les dictionnaires en graphie classique coupant donc le lien étymologique avec vitis - et variantes tant orthographiques que phonétiques vijana, aviçana $(1 .: 34)$, raviçana $(1 .: 30 \mathrm{C} ; \mathrm{p} .: 13)$ et certainement bien d'autres. 
Figure 17. - Clématite vigne blanche (Clematis vitalba) - Redòrta, Aubavit, Vidalba, Vinha blanca, Viçana.

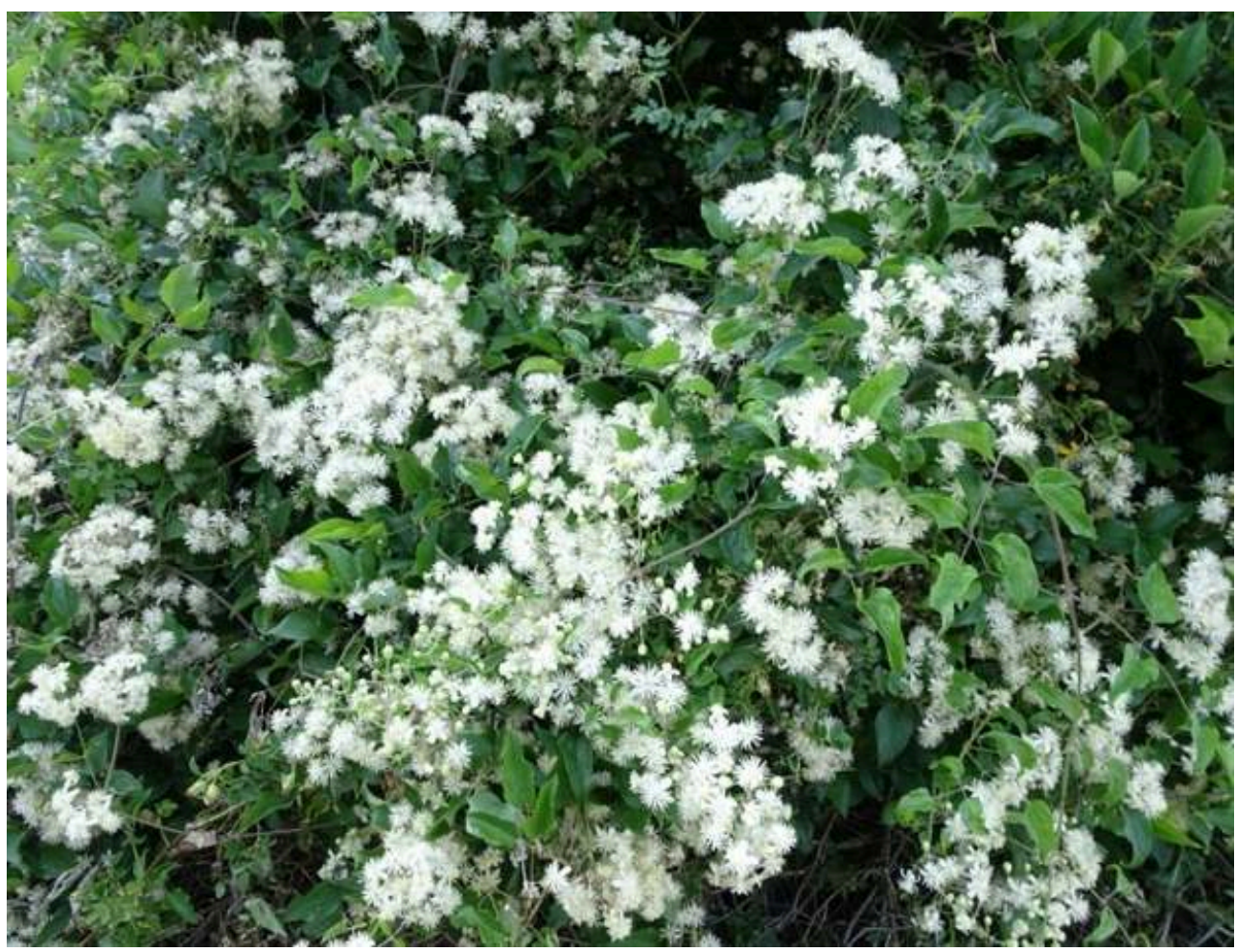

Photo : Josiane Ubaud.

Figure 18. - Clématite flammette (Clematis flammula) - Entrevedilh, Entrevadís.

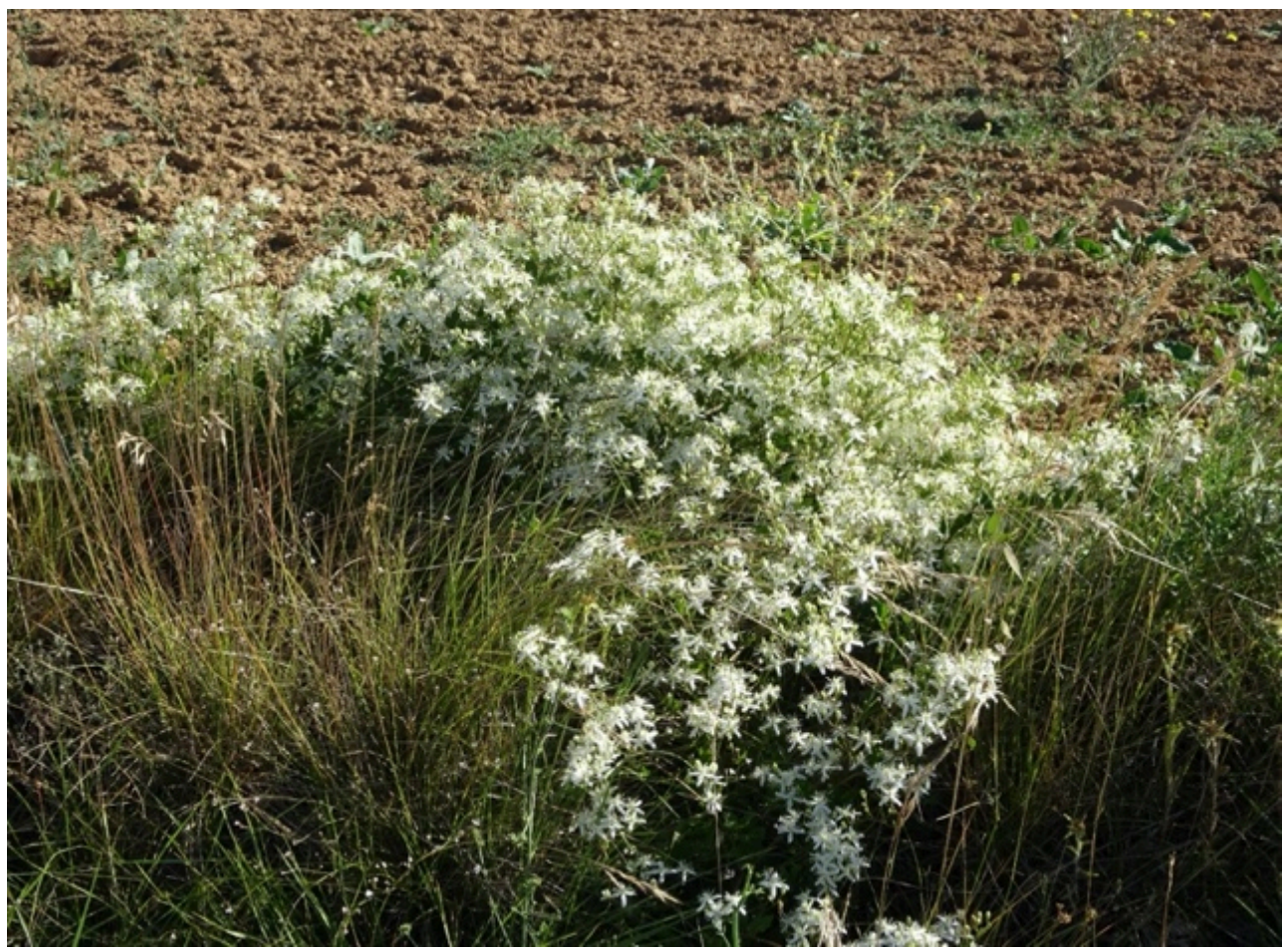

Photo : Josiane Ubaud. 

(Narcissus poeticus). Hélas les dictionnaires et encore plus les atlas mélangent les espèces... La liste des divers vocables occitans est disparate au possible et certains peu clairs de sens. Ils sont tous donnés groupés à diverses entrées du dictionnaire d'Honnorat (1845), chacun n'étant pas repris forcément en entrée autonome, mais rarement avec localisation. On y constate des mélanges entre les espèces et des contradictions entre les entrées :

- «DONA, s. f. Madona, Belori, Germana, Crebidola, Aleda, Aledra, Aneda, Ardela, Berbeluda, Adrela, Clariana, Jusiouva, Jusueva, Flour de Pasquas, Pasqueta, Curbidona. Noms sous lesquels on désigne en divers lieux le narcisse des poètes. » (p. 746)

- «PISSAULIECH, s. m. Mau de tèsta, Campaneta, Jusiouva, Jounquilha salvagea [visiblement pris à Boissier de Sauvages]. Est le nom qu'on donne au narcisse de Constantinople, ou narcisse à bouquets, Narcissus tazetta. » (p. 1653)

- «TROUMPOUN, s. m. Ayault, Cougut, Jounquilha. Narcisse, faux-narcisse, narcisse des prés. » (p. 2096)

- « GERMANA, s. f. Nom qu'on donne à Cruis [04] au Narcisse des poètes. » (p. 1105) 
- «JONQUILHA, s. f. Jonquille sauvage et cultivée, Narcissus jonquilla. » (p. 1243)

- «JOUNQUILHA, s. f. On donne ce nom dans les environs de Riez [04] au Narcisse des poëtes.

V. Dona. »

- «JOUNQUILHA-SALVAGEA, s. f. Nom toulousain du narcisse tazette. V. Pissauliech. »

61 Nous allons essayer d'analyser un peu le corpus. On note la référence à des oiseaux : si on peut comprendre ganta n.f. (l.:12), nom de l'oie, blanche comme la fleur, on a plus de mal avec aneda n.f. (l. : 30C) (ALLOR), aleda / aledra n.f. (1. : 30) (Boissier de Sauvages, 1820), car toutes les canes ne sont pas blanches - mais s'agit-il de canes ici ? on verra le doute plus loin - , tout comme avec pola-madòna n.f. (1.:34), poule-madame, que nous ne savons pas analyser.

La référence au printemps se lit dans flor de mai n.f. (p.: 84, 04), fleur de mai, tout en notant que le printemps en plaine au bord de mer vient beaucoup plus tôt qu'en zone de l'arrière-pays, semi-montagne ou montagne. Un phytonyme par rapport au mois de mai, c'est peut-être déjà trop tard pour la plaine et bien trop tôt pour la montagne. Encore un nom qu'il est impensable de transporter pour n'importe quelle région, anachronisme devant lequel ne reculent point les compilateurs. Pasqueta n.f., flor de Pascas n.f., sont pareillement rattachables au printemps, par l'intermédiaire de la fête de Pâques.

Le nom de corbadòna n.f. (1.: $30 ;$ p. : 84), variantes curbidòna (p. : 84), corbidona, et même crebidòla selon Mistral, la dame penchée, renvoie à une des caractéristiques physiques des narcisses en général et du Narcisse des poètes en particulier : il a la tête inclinée à la cime de sa tige. Doit-on y voir la référence au statut social imposé autrefois aux femmes de ne jamais avoir les yeux levés mais baissés? On y rattacherait sémantiquement madòna n.f. (madame, madone) et peut-être aussi le nom de domaisèla n.f. (1. : 30), en raison de plus de la couleur blanche, couleur de la virginité. On trouve la même observation de la fleur penchée pour la violette, qui lui vaut le nom similaire de captòrta n.f. (l. : 12), la tête tordue. Par le blanc, on trouve flor de cementèri n.f., fleur de cimetière, qui concerne bien le Narcisse des poètes car rattaché au fait que l'on en ornait les tombes des enfants, traditionnellement voués au blanc comme couleur de deuil. D'ailleurs, il ne fallait point leur en offrir de leur vivant, sous peine de leur porter malheur.

Campaneta n.f. (1. : 34) donné par l'ALLOR pour Pézenas (34) sans précision d'espèce, est déjà restitué par Honnorat (1845): "Nom qu'on donne aux environs de Gigean, (Hérault), selon M. de Belleval, au Narcissus tazetta » (p. 391). La profusion de fleurs en fait un regroupement de clochettes, qui lui vaut par ailleurs le nom de narcisse-muguet. Le nom de cotèla n.f. (l. : 30) renvoie à la forme en lame plane des feuilles des narcisses en général, ce nom pouvant nommer aussi d'autres plantes à bulbes ou rhizomes et aux feuilles visuellement encore plus proches d'un couteau (cotèu, cotèl) comme les iris, les glaïeuls. 
Figure 19. - Narcisse des poètes (Narcissus poeticus) - Corbadòna, Madòna, Belòria, Ganta.

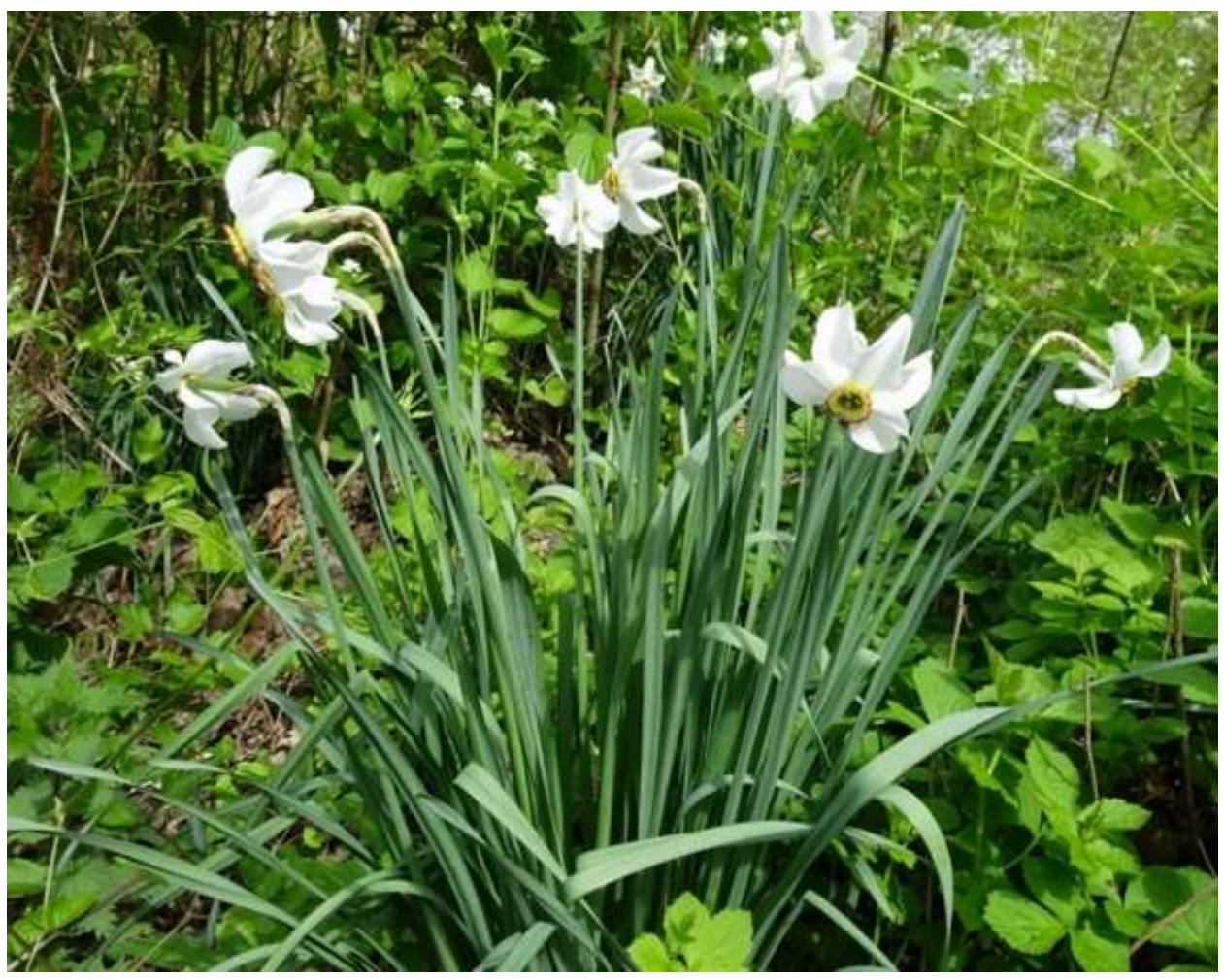

Photo : Josiane Ubaud.

Figure 20. - Narcisse-trompette, Jonquille (Narcissus pseudonarcissus) - Cocuda, Judieva, Trompon.

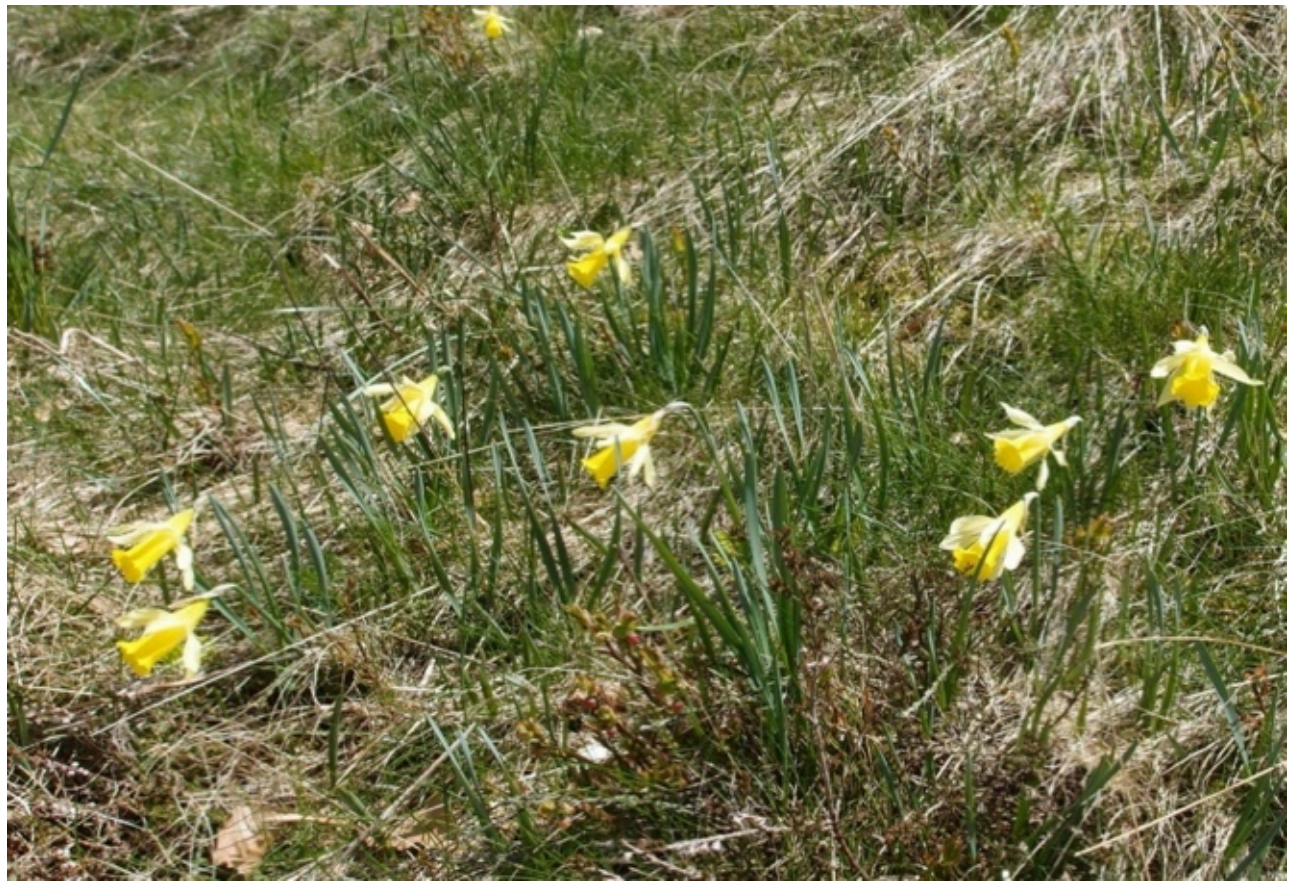

Photo : Josiane Ubaud. 
Figure 21. - Narcisse tazette (Narcissus tazetta) - Mau de tèsta, Narcisse-muguet, Campaneta.

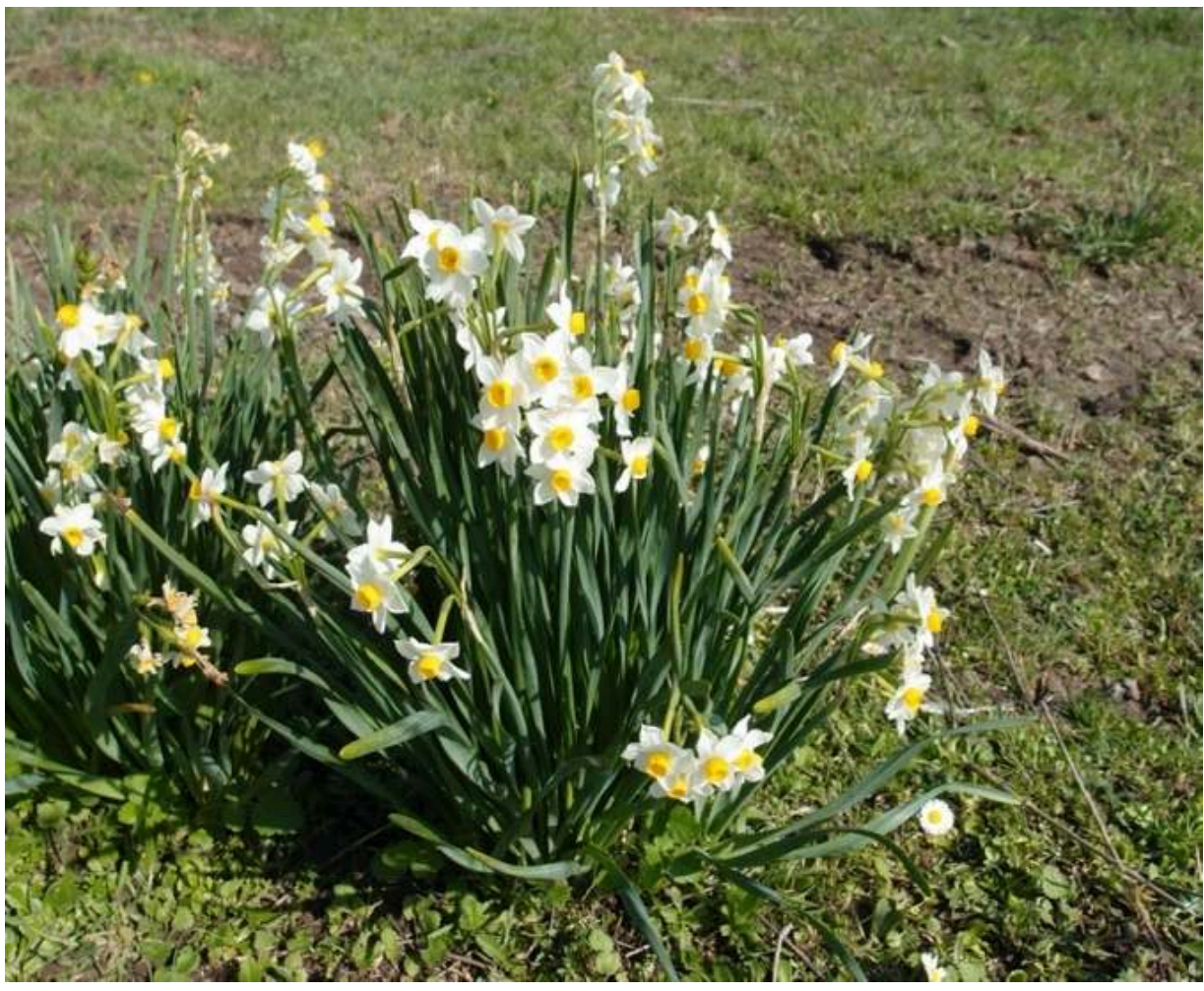

Photo : Josiane Ubaud.

La forte odeur des narcisses qui peut incommoder certaines personnes, explique le nom de mau de tèsta n.m. (l. : $34 ;$ p. : 84), trincatèsta n.m. (l. : 30) - encore avons-nous un gros doute sur le fait que ce soit bien le Narcisse des poètes donné par l'ALLOR pour Gallargues (34), et pour Marsillargues (30), où les prés abondent de Narcisses tazettes, à odeur tout aussi entêtante. D'ailleurs Honnorat, repris par Mistral, donne clairement « mau de tèsto, Narcisse à bouquets ». Ou peut-être encore, par image interposée celui de pechier n.m., le pichet à vin car les narcisses enivrent autant que le vin, et certaines personnes ne peuvent dormir proches d'un bouquet de narcisses sous peine d'avoir la tête lourde comme après avoir bu trop de vin. Mais variations des sources... Honnorat (1845) cite Garcin (1841) : « Mr Garcin le définit ainsi : Grand narcisse simple ; c'est probablement du narcisse faux poète qu'il veut parler, parce que sa fleur simple a quelque rapport avec un pot d'eau.» (p. 1588) Pot à eau, pot à vin? Pechier est donné clairement comme une pinte de vin... On notera que la fleur du Narcisse des poètes est aussi «simple » que celle du Narcisse faux-poète (appellation botanique et non pas populaire).

66 Nous réfutons également le vocable cocuda n.f. (1.: 34), variante coiola n.f. (1.: 30$)$, pour le Narcisse des poètes, car la référence au coucou (cocut, coguiòl, coguiòu, coiòu) est majoritairement attachée à des fleurs jaunes (la Primevère officinale par exemple) et nous avons relevé ce nom pour Narcissus pseudonarcissus en Cévennes, tandis que Mistral le donne aussi en Rouergue. Si l'ALLOR consacre bien un petit paragraphe dans la carte «Iris » $\left(\mathrm{n}^{\circ} 160\right)$ et énumère certains des noms ci-dessus, il a malheureusement pour titre "Narcissus poeticus et autres », mais " autres » ne sont jamais précisés : ces formulations nous surprendront toujours pour des ouvrages se voulant scientifiques qui ne devraient présenter que des cartes « ce taxon = quel nom? ». Encore une fois, 
botanistes et amateurs de mots dialectaux ne sauront jamais à quelle espèce se rattachent précisément les noms donnés par l'atlas, où s'entrecroisent, au vu des points d'enquêtes, les noms du Narcissus poeticus (grande fleur blanche, courte couronne jaune pâle ourlée de rouge), du Narcissus tazetta (petites fleurs réunies par 5-10 au sommet de la tige, blanc crème, plus rarement jaune, à la couronne orange vif), du Narcissus pseudonarcissus (grosse fleur entièrement jaune, à la couronne jaune vif très proéminente) appelé abusivement jonquille, car il n'a pas les feuilles cylindriques en forme de jonc.

67 Le même abus de langage est attesté pour l'occitan par Boissier de Sauvages déjà vu précédemment: "Jounquilha, s.f. Jonquille sauvage et cultivée, Narcissus jonquilla. Jounquilha, s.f. On donne ce nom dans les environs de Riez au Narcisse des poëtes. V. Dona. [...] Jounquilha-salvagea, s. f. Nom toulousain du narcisse tazette. V. Pissauliech. » Mistral reprend l'équation jonquilha $=$ jonquille, mais aussi jonquilha $=$ Narcisse des poètes, et détourne l'entrée languedocienne jonquilha salvatja de Boissier de Sauvage en jonquilha fera, l'adjectif salvatja ne s'employant pas en provençal : il laisse donc croire que l'appellation jonquilha ferra est attestée en provençal. Pour de nombreuses entrées chez Mistral, on ne sait point qui est le dialecte-source attesté (du languedocien? du provençal ?) dont il donne l'équivalent théorique dans l'autre dialecte, sans que l'on ait la moindre assurance de son existence. Il convient de noter que si l'espèce Narcissus jonquilla existe bien, à fleurs groupées entièrement jaune vif et donc à feuilles en forme de jonc, elle n'est pas présente dans la flore sauvage française mais en Espagne, et est vendue effectivement comme plante cultivée. Encore existe-t-il en terres occitanes deux autres petits narcisses des garrigues à fleurs groupées: Narcissus assoanus jaune vif, à feuilles de jonc (autrefois Narcissus juncifolius), et Narcissus dubius blanc pur, à feuilles planes, jamais identifiés / identifiables dans les dictionnaires.

Pour la région de la Margeride, le nom de tèsta n.f. (l. : 48) fait référence à une cueillette traditionnelle des têtes de Narcissus poeticus pour l'industrie des parfums, à l'aide d'un grand râteau qui ne moissonne que les têtes, seules intéressantes. Pour le vocable tiravacas n.f., Mistral hésite entre « qui trait les vaches » (leur diminue le lait?) ou « qui attire les vaches" (qui en seraient friandes?): il manque visiblement des renseignements auprès de locuteurs. Pour belòria n.f. (p. : 04) signifiant «parure, bijou, ornement ", faut-il en déduire que la fleur était particulièrement admirée, car belle comme un joyau? Nous osons un parallèle, mais avec toute la prudence possible, avec margarita, désignant la perle en latin, qui a ensuite glissé sur le nom de la fleur marguerite au sens large (margarida en occitan), elle aussi d'un blanc pur. Les vocables porracha berbeluda et porracha margarida n.f. (l.:07S) donnés par l'ALLOR, montrent la distinction entre deux narcisses, porracha fonctionnant un peu comme nom de genre, dérivé dépréciatif de poireau (pòrre), à cause de leurs feuilles rubannées. La grande asphodèle (Asphodelus ramosus) peut aussi porter le nom de porraca / porracha pour la même raison. Porracha margarida semblerait de toute évidence être le Narcisse des poètes, blanc comme une marguerite. Pour la précision porracha berbeluda, donnée aussi en nom seul sous la forme barbeluda n.f. $(1 .: 07 \mathrm{~S}, 30 \mathrm{~N})$ pour une autre espèce (N. pseudonarcissus?), nous ne comprenons pas le sens de prime abord. La morphologie $\mathrm{du}$ vocable indique qu'il s'agit d'une fleur pourvue de "barbèla», lequel vocable ne renvoie qu'à la femelle du barbeau, poisson pourvue de "moustaches ». Qu'est-ce qui peut faire penser à des moustaches, à des petites barbes, chez N. pseudonarcissus? Sa couronne est particulièrement crênelée, "barbelée »: est-ce l'explication? Et pour éclaicir le tout, on relève une contradiction entre l'ALLOR et le dictionnaire d'Honnorat 
qui donne au contraire «berbeluda, un des noms languedociens du Narcisse des poètes » et non le narcisse jaune.

Revenons sur aleda, aledra $(1 .: 30 \mathrm{~N})$, clairement donnés comme noms possibles de la cane. Mais l'homonymie vient obscurcir l'analyse, car ce sont aussi des appellations pour les asphodèles, variantes de alapeda (< latin asphodelus, fer de lance). Aleda n'est donc peut-être pas à rattacher à la femelle du canard (parce qu'on a déjà l'analogie avec un oiseau par ganta et pola-madòna) mais plutôt à l'asphodèle, qui sert déjà de référent dans les noms ci-dessus construits sur porracha, toujours à cause de la feuille rubannée, terminée plus ou moins en pointe, qu'ont et les narcisses et les asphodèles. Boissier de Sauvages, repris par Honnorat, fait clairement deux entrées aledra (cane ; narcisse).

Restent les énigmatiques chichet n.m. (1.: 12), germana n.f. (p. : 04), clariana n.f. (p. : 04) (« nom des [sic] narcisses à Colmars (Basses-Alpes) ») d'après Honnorat, non affectables à une espèce a priori et de sens non transparent. Et un curieux pissa-au-liech n.m. restitué par Honnorat pour le Narcisse tazette. Si le mot est clair de sens, pissenlit, comme la salade bien connue, on en cherche cependant la cause car n'étant pas comestible, il ne saurait être diurétique. Et point de narcís dans les atlas, fleur pourtant ainsi nommée depuis les Latins? Parmi tous nos grands dictionnaires, seul le dictionnaire d'Honnorat (1845) donne un narcisse en général (pouvant donc fonctionner comme nom de genre), au sujet duquel il précise «deux plantes portent ce nom, le narcisse des poètes, v. dona, et le faux narcisse des poètes, v. troumpoun", tandis que Mistral donne de plus narcisse-muguet pour Narcissus tazetta. Comment un nom aussi antique et chargé de mythologie a-t-il pu se perdre ainsi en route ? On ne le trouve pas davantage en occitan classique dans le lexique roman des troubadours de Raynouard (1844). On le trouve par contre chez les écrivains contemporains usant d'un occitan plus normé et/ou ayant perdu un occitan localisé de famille.

Que deviennent les entrées données par les lexicographes anciens dans certains dictionnaires postérieurs? Comme déjà montré ci-dessus pour d'autres végétaux, les auteurs s'y livrent à des croisements de noms entre Narcissus poeticus et Narcissus pseudonarcissus. Dans le dictionnaire français-provençal de Coupier entièrement repris à Mistral (en graphie mistralienne, 1995), on peut ainsi lire : «NARCISSE. s. $1 \cdot$ (bot.) : courbo-dono, pasqueto ; judievo, judiéuvo ; belòri (f.), troumpoun (m.). » On retrouve l'usage du singulier abusif pour narcisse, car il y a des narcisses bien distincts, et le mélange des noms des deux espèces répandues, sans précisions. Or, si corbadòna, pasqueta et belòria concernent Narcissus poeticus, judieva et trompon ne peuvent concerner que Narcissus pseudonarcissus, tous deux pourtant bien renseignés chez Mistral, qu'il suffisait de recopier à l'identique. Judieva (la juive) renvoie en effet à la couleur jaune (donc toute une histoire et une symbolique relatives à l'usage de cette couleur) et trompon mentionne combien la couronne centrale de ce narcisse est proéminente, en forme de trompette : elle porte aussi le nom de Narcisse-trompette en français. On est donc fort loin du Narcisse des poètes. Voilà un exemple parmi tant d'autres de toutes les erreurs botaniques et linguistiques plus ou moins lourdes que l'on peut trouver dans les dictionnaires contemporains issus de compilations des dictionnaires antérieurs, eux-mêmes non exempts d'approximations. Pour juger de la qualité d'un dictionnaire, il nous suffit d'ailleurs de consulter quelques entrées botaniques, plantain, genévrier, pin, etc., en plus de quelques verbes complexes car nécessitant un tri sémantique. diverses mais confondues en enquêtes sous le nom au singulier «le narcisse » et de 
ceux contenus dans les dictionnaires, parfois contradictoires et mal recopiés par leurs suiveurs? Que corbadòna, ganta, belòria, flor de cementèri, concernent Narcissus poeticus ; que judieva, cocuda, trompon, concernent Narcissus pseudonarcissus, par la couleur jaune et la forme en trompette de la couronne; que campaneta, mau de tèsta, narcisse-muguet, jonquilha salvatja, concernent Narcissus tazetta. Pour les autres noms, on s'empressera de n'être point péremptoire.

\section{Noms locaux occitans vs noms génériques occitans et « noms français »}

73 Cette enquête sur les noms locaux, si passionnante soit-elle, ne doit point faire oublier une autre problématique à laquelle nous sommes confrontée en tant que formatrice et conférencière: quels noms utiliser lorsque l'on a un public de toutes origines dialectales, c'est-à-dire quels noms plus normatifs, plus génériques, d'une plus vaste compréhension en termes d'aires géographiques. Si c'est évidemment du descriptif que l'on peut déduire une forme centrale compréhensible par plus de gens, le peu de sources anciennes concernant les noms de plantes - autres que les médicinales bien présentes dans les textes du Moyen Âge - n'aide guère. D'autre part, la parcellisation extrême des paroles est due à l'interdiction de l'occitan écrit depuis des siècles. Si des renaissances de cet écrit ont eu lieu, elles n'ont concerné que l'aspect littéraire hélas (prose ou plus souvent poésies) dont l'objectif n'était certes pas (ou du moins rarement) de restituer le lexique des végétaux. Des médecins, des botanistes, eussent-ils écrit régulièrement qu'ils auraient dicté la norme. De ce fait, comment savoir si telle plante n'a pas connu une unanimité d'appellation au Moyen Âge - la langue écrite y présentait alors une grande unité transdialectale -, qui s'est ensuite effacée devant le morcellement de la langue dû à son cantonnement à l'oralité ? Pour communiquer plus largement, car nous nous inscrivons dans une démarche de transmission et d'avenir de la langue, revenir à l'étymologie le plus souvent possible est donc la seule solution envisageable, même si sur le terrain, les enquêtes ne montreraient pas cet usage le plus répandu actuellement, donc limité en termes d'aires sur les cartes des atlas.

Nous sommes ainsi amenées à jongler en permanence entre le descriptif des noms locaux et le normatif des noms plus génériques, communiquer local / communiquer et surtout écrire large, pour répondre entre autres aux demandes de lexiques de botanique ou d'étiquetages de sentiers botaniques, et assurer des cours de formation. Car nous ne pouvons raisonnablement venir « avec les atlas sous le bras » ou nos fiches détaillées, pour réciter à chaque cas la litanie des noms d'un seul végétal. La nécessité de dégager un tant soit peu un métalexique occitan se montre nécessaire, pour une intercompréhension dialectale maximale. Mais la tâche est loin d'être facile, voire impossible pour certains cas. Pour les quelques cas étudiés ci-dessus, nous usons prioritairement des formes directement issues de l'étymon ou de celles faisant l'unanimité : euse, rove, pibola, auba, cade, genebrier, morven, ferigola, sarsaparilha, narcís. Et pour un étiquetage d'un sentier ethnobotanique, nous userions d'une forme générale, suivie d'une forme plus locale dans la mesure où elle peut être encore récoltée.

On ne peut évoquer ces problèmes de transmission des noms occitans sans évoquer celui parallèle "des noms français». Des pseudos-noms français empressons-nous de dire... Car ce foisonnement des noms occitans sert parfois d'un argument de plus pour 
dénigrer « les patois », par rapport au français unique qui ferait l'accord sur toutes les plantes en une bijection parfaite selon l'harmonie supposée " un taxon = un nom ». Comment prétendre que la végétation spécifique méditerranéenne peut être nommée " en français ", puisque ce n'est pas cette langue qui était la langue de ces espaces? Nous sommes pourtant encore amenées à rappeler ce pléonasme : c'est la langue d'un pays qui dit la végétation de ce pays. C'est la langue vietnamienne qui dit la végétation vietnamienne, le pays fut-il un temps colonisé par des puissances usant d'autres langues. C'est la langue inuit qui décrit la neige (cinquante vocables environ), pas le français ou l'anglais.

Beaucoup de flores présentent donc comme «noms français » ce qui n'est en fait que la traduction du binôme latin, et certes pas un nom vernaculaire. Coquelicot, ponceau, marguerite, aulne, saule, sont des noms français. Aphyllanthe de Montpellier, Reichardie en forme de picride, Crépide fétide, Crépis saint, Inule visqueuse, ne sont pas des noms français mais la traduction des noms latins botaniques Aphyllanthes monspeliensis, Reichardia picroides, Crepis foetida, Crepis sancta, Inula viscosa, plantes qui n'existent pas en terres de langue d'oïl. Lesquels noms latins changeront au gré des variations de la nomenclature, beaucoup de botanistes se faisant un plaisir de reprendre les noms pour laisser leur empreinte, quitte à revenir en arrière quelques années plus tard. Par contre ces plantes ont toutes des noms occitans, bragalon, costelina, tèrragrèpa, morre pudent, pata de galina, èrba rossa, limbarda, stables sur une aire donnée.

Donc même le latin, métalangue des botanistes, n'est pas solide comme un roc en matière de noms de genres ou d'espèces. Il ne l'est pas davantage à propos des noms de familles puisqu'il y a actuellement plusieurs nomenclatures en vigueur (classification classique, classification phylogénétique). Les valses-hésitations des binômes latins sont donc innombrables, nous n'en donnerons que quelques-unes et leurs incidences sur les « noms français ». Le Crepis sancta actuel a été autrefois Pterotheca nemausensis, Lagoseris nemausensis, ce qui lui a valu / vaut les «noms français » de Crépis saint ou Crépide sainte, Ptérothèque de Nîmes, Lagosérie de Nîmes, selon les dates des sources. En occitan, c'est l'èrba rossa, la pata de galina (l. : 30) passés au français dit régional Herbe rousse, Patte de galine. L'Inule visqueuse toujours qualifiée ainsi dans bien des flores est pourtant devenue Dittrichia viscosa : où est la logique? La première orchidée des garrigues à fleurir s'est vue baptisée / débaptisée très souvent: Orchis robertiana, Loroglossum longibracteatum, Barlia robertiana, pour finir actuellement Himantoglosssum longibracteatum, jusqu'au prochain changement, avec chaque fois bien sûr le «nom français » traduit du latin pour certains, ou au contraire arrêté sur un de ses noms précédents (la Barlie de Robert). Or, les allergiques aux noms régionaux usent de cet argument de l'infaillibilité supposée des noms latins pour justifier leur mépris annexe des noms "patois » si divers, changeants, peu sûrs. Noms latins et noms vernaculaires concernent des grilles de lecture du réel différentes et qu'il est vain de vouloir hiérarchiser.

Pourquoi donc continuer à qualifier comme "noms français" des noms qui ne sont certes pas des noms vernaculaires et qui changent en permanence, et non pas l'adaptation française des noms occitans en usage chez bien des habitants qui eux sont immuables sur un territoire ? Pourquoi ne pas appliquer la même recette linguistique qui fait que nous disons yucca (de l'haïtien), toundra, taïga (du russe), nems (du vietnamien), taboulé (du libanais), toutes spécialités non françaises? Lesquelles ne sauraient donc avoir pour noms français que l'adaptation orale de leurs vocables 
d'origine. Ces évidences pour les langues étrangères deviennent étrangement des blocages pour les langues historiques de France. En terres occitanes, on va donc cueillir des terregrèpes (1.), des coustelines (p.) (et non des réchardies), et les moutons y broutent la bauque (et non le brachypode rameux, toujours appelé ainsi alors qu'il a été débaptisé en B. retusum) et le bragalon (et non l'aphyllanthe). Ces problèmes se posent avec acuité lorsqu'il s'agit de passer de l'occitan au français pour des traductions d'œuvres d'auteurs, aussi bien pour des traducteurs extérieurs que pour les auteurs se traduisant eux-mêmes, beaucoup répugnant / hésitant à assumer nos spécificités floristiques donc lexicales en employant du pseudo-français au lieu d'occitan adapté, voire en commettant des contre-sens complets.

\section{Conclusion}

L'analyse des sources écrites montre donc leur très grande faiblesse, soit en matière de botanique, soit en matière de linguistique, soit les deux réunies pour les travaux les plus récents. Si l'on ne peut empêcher personne de produire des compilations hasardeuses ou erronées, il faudrait par contre refaire toutes les cartes botaniques des atlas, en reprenant le travail tel qu'il aurait dû être mené dès le début :

- s'assurer la présence d'un botaniste pour bien montrer la plante dont il est question à l'informateur, sans ambiguïté, ce qui semblerait élémentaire a priori. Jamais un botaniste n'aurait posé la question «comment nommez-vous le chêne? le plantain ? le genévrier? le narcisse? » puisqu'il sait que ce singulier n'a strictement aucun sens, tant il y a de chênes et de plantains et de genévriers et de narcisses radicalement différents et dans la forme et dans l'usage et parfaitement identifiés populairement. Jamais un ethnobotaniste connaisseur du fonctionnement des appellations populaires n'aurait posé la question sous cette forme, car il sait que l'on ne peut placarder la grille de lecture des uns sur la lecture des autres ;

- s'assurer le contrôle d'un connaisseur de la langue en amont pour valider ou pas les réponses de l'informateur. Jamais un ethnobotaniste en occitan n'aurait validé morcible et lachuscla, juscla, chuscla pour le Silène enflé. Formulé autrement, toute parole émise par un informateur n'est point parole d'évangile, enregistrable pieusement dans les atlas, sans analyse. Lorsque nous sommes en présence d'un informateur qui visiblement se trompe de plante ou de nom (nous commençons à connaître beaucoup de noms...), nous n'enregistrons pas le vocable. Mais si c'est déjà l'enquêteur qui se trompe de plante, ou que la plante n'est même pas montrée...

Or si la volonté de réaliser des atlas fut plus que louable, et indispensable, ces erreurs de méthodologie qui ont présidé à leur réalisation impactent encore négativement notre langue et notre culture, car c'est par les noms populaires que l'on accède à la culture d'un peuple, groupe ou ethnie, que ce soit pour les plantes, les objets artisanaux, l'architecture ou les recettes de cuisine. C'est par les noms populaires, non entachés d'erreurs, que l'on peut établir des ponts entre les différents dialectes (en rattachant toutes les variantes à une forme centrale dont elles dérivent) et les différentes langues (ici romanes) ou au contraire constater les écarts lexicaux et culturels. Les sources issues d'organismes officiels se doivent donc d'être exemplaires et non d'un niveau d'amateurs. Ainsi, nous travaillons souvent en parallèle avec les noms catalans des végétaux, langue bien plus avancée que la langue occitane, car elle n'a jamais perdu du terrain, et aux productions écrites bien plus rigoureuses. La 
similitude de l'héritage culturel gréco-latin y apparait bien évidemment, même pour les noms motivés, qui sont souvent l'expression d'un même regard donnant des phytonymes très voisins voire identiques, et souvent en rapport avec les noms latins anciens (similitude que l'on rencontre pareillement au niveau des contes classés par thèmes récurrents à l'échelle européenne). Ainsi, les champignons toxiques du genre Boletus se nomment mataparent en catalan et maçaparent en occitan cévenol (le tueur de parents, par ironie). Pour le Chêne vert, eusina / ausina en occitan, alzina en catalan ; pour le Pin d'Alep, pin blanc en catalan comme en occitan; pour le Nerprun alaterne, aladèrn dans les deux langues; pour la Clématite vigne blanche, vidalba, redòrta en occitan, vidalba, ridorta en catalan, et des dizaines d'autres exemples.

81 Enquêter sur les noms locaux est donc loin d'être un isolement, fractionnement, repliement sur les dialectes : c'est au contraire donner accès à du liant, pour ce qui concerne ce qui est comparable, comme l'a montré Michel Contini (1986) pour les noms européens des plantains. On accède à une culture et un imaginaire qui nous relient aux ancêtres, car l'occitan est une langue beaucoup plus latinisée que le français et bien des phytonymes occitans sont identiques aux noms gréco-latins anciens repris en noms botaniques : sambuc / sureau, avelanier / noisetier, api / céleri, ceba / oignon, vesc / gui. Ils disent aussi le même regard porté sur une plante à des millénaires d'écart: tragopogon, la barbe-de-bouc (le salsifis) en latin, du grec signifiant barbe de bouc, se dit pareillement barbaboc ou bochibarba en occitan, à cause de la forme de son infrutescence en barbichette lorsqu'elle n'est pas totalement épanouie. Phytonymie qui nous relie aussi aux peuples contemporains de la romanité. Par les divers noms dialectaux occitans sambuc, saüc, sambequier n.m. (du latin sambucus, nom du Sureau noir), nous accédons au catalan saüc n.m., à l'espagnol saúco n.m., à l'italien sambuco n.m., au corse sambùcu n.m., au portugais sabuguero n.m., accès auxquels ne donne pas le français sureau. Par l'occitan persèc / pressèc n.m. (l.), persègue n.m. (p.), nom de la pêche (du latin pomum persicum, fruit porté par Prunus persica), nous accédons à l'italien pesca n.f., au corse pèrsica n.f., au catalan prèssec n.m., au portugais pêssego n.m., le sens de « (fruit) de Perse » n'étant plus lisible dans la forme française pêche (ancien français pesche).

82 Si la faiblesse des atlas linguistiques doit être soulignée car elle est loin d'être anecdotique, on doit déplorer aussi l'absence de travaux réels d'ethnobotanique en terres françaises et a fortiori en langues minoritaires, au profit quasi exclusif de recherches en terres lointaines, l'exotisme ayant toujours été vécu comme seul digne d'intérêt car un signe patent d'ouverture au monde (?), au mépris des savoirs populaires locaux jugés « ringards patoisants ».

Doit-on rappeler le mépris et les moqueries qu'ont ainsi essuyé des Paul Sébillot, Claude Seignolles et autres "folkloristes ", mot péjorativement employé en français mais pas en anglais? Le retour aux usages des plantes tant alimentaires et médicinaux qu'agricoles et domestiques, usages ô combien écologiques, entièrement maîtrisés par nos ancêtres depuis des générations, montre combien ce fut une très grave erreur anthropologique de les avoir relégués au rang de savoirs en bas de l'échelle, forcément non opératoires, pour ne pas dire superstitieux, et tellement archaïques avec sens négatif (issus d'héritages culturels depuis des millénaires, donc archaïques au sens totalement positif), donc sans le moindre intérêt. Ce fut le thème de l'Université occitane d'été de Nîmes (juillet 2020) où nous avons été plusieurs intervenants à montrer la pertinence de ces savoirs face aux questions écologiques contemporaines. La 
rupture des savoirs, par refus de l'héritage, n'a jamais fait avancer l'humanité, ni sur le plan individuel, ni sur le plan collectif.

Une approche rigoureuse de ces savoirs doit donc être impérativement menée, non comme sur un papillon chloroformé, mais bel et bien pour être enseignée, transmise, réinjectée dans la société, pour sauver dignement ce précieux capital culturel et linguistique dont l'homme contemporain a bien des leçons à tirer : c'est avec la langue de son territoire, pas avec celle des autres, que l'on appréhende son environnement, qu'on le gère et qu'on l'exploite avec respect, le retour aux méthodes douces d'agriculture en étant un parfait exemple. C'est en tout cas notre souci constant : nous ne collectionnons pas pour collectionner et constituer un magot personnel mais pour transmettre, et renouer les liens perdus humain / nature / culture, au lieu de l'hommemachine décrété hors-sol d'aujourd'hui. Nous laissons encore la parole à Jacques Barrau (1983) (lequel, curieusement, n'a pas travaillé sur les savoirs naturalistes français, mais en pays « exotiques») :

Je tenterai d'abord d'esquisser très brièvement et sommairement l'histoire de la prise en compte scientifique de l'étude des relations entre les hommes, leurs environnements naturels et les ressources de ces environnements.

Je remarquerai tout d'abord que cela ne posait guère de problèmes à la vieille « histoire naturelle». Relisez donc celle de Pline qui, au début de notre ère, fit figurer, par exemple, dans son Historia naturalis un chapitre intitulé De diversitate caseorum, «De la diversité des fromages "; c'est assez dire que ce que les hommes font de la nature et de ses ressources faisait tout naturellement partie de ses préoccupations!

Mais avec le temps et avec le progrès de la connaissance scientifique s'individualisèrent et s'affirmèrent des disciplines scientifiques qui, à compter du $\mathrm{XVIII}^{\mathrm{e}}$ siècle, eurent de plus en plus tendance à étudier les objets et phénomènes naturels en eux-mêmes et pour eux-mêmes en reniant peu à peu les préoccupations utilitaires et humanistes de l'ancienne «histoire naturelle ». Les hommes furent ainsi exclus de la nature et les scientifiques qui étudiaient cette dernière en vinrent à considérer ces hommes comme des perturbateurs et destructeurs des chers objets de leurs recherches. Quant aux savoirs « populaires » des choses de cette nature, ce n'était, pour la grande majorité de ces savants, que fables ridicules et donc sans intérêt. (p. 5-12)

Furent exclus et le sont encore par idéologie affichée ou négligence... coupable. Voir enquêter en terres occitanes, bretonnes, catalanes, sans connaître les langues de ces territoires et en prétendant de plus que cela n'est point nécessaire, relève à nos yeux de l'imposture, car on en sait l'explication : pourquoi enquêter dans un " patois » qui n'est pas une langue? On se contente d'enregistrer des sons que l'on transcrits avec ceux d'une autre langue. D'où l'évidence: faire de la dialectologie et de l'ethnobotanique, c'est aussi faire de la sociolinguistique, puisqu'il entre en jeu une hiérarchisation des langues a priori, avec langue de prestige dominante / langue inférieure dominée n'ayant pas besoin d'être considérée comme une langue, comme démontré pour les exemples ci-dessus, notamment le secteur de l'olivier. Bien évidemment cela ne concerne pas les atlas pour le côté linguistique, dont les noms sont rigoureusement transcrits, mais pour les quelques études menées par des ethnobotanistes monolingues francophones. Les Occitans occitanophones sont-ils exempts de critiques dans l'absence de ces travaux ? Hélas non, le corollaire de la hiérarchisation des langues c'est d'inculquer un réflexe de diglossie, ajouté de plus à l'extrême politisation du milieu dans les années 1970 qui a aussi imposée sa marque : travailler sur la nature n'était pas "progressiste », voire totalement "réactionnaire", donc avec une péjoration identique à celle du mot 
folklore. Il n'y eut donc point d'études ni en botanique, ni en ornithologie, ni en entomologie, à une époque où il restait encore beaucoup de locuteurs pour en parler. Il est urgent d'en tirer les conclusions qui s'imposent, si ce n'est pas déjà trop tard en ce qui concerne tous ces savoirs naturalistes en langues dites régionales, pourtant bien plus riches de sens que le seul savoir imposé d'en haut, car en totale adéquation avec leurs territoires.

\section{BIBLIOGRAPHIE}

Atlas linguistique de la France (ALF), (1902-1910), Jules Gilliéron \& Edmond Edmont, Honoré Champion, Paris. Carte $n^{\circ} 265$ « Chêne (un beau -) », <http://lig-tdcge.imag.fr/cartodialect5/\#/ visualiseur>.

Atlas linguistique et ethnographique du Languedoc oriental (ALLOR), 1981, Jacques Boisgontier, Paris, CNRS.

Atlas linguistique et ethnographique de Provence (ALP), 1975, vol. I, Jean-Claude Bouvier \& Claude Martel, Paris, CNRS.

Atlas linguistique et ethnographique de Provence (ALP), 1979, vol. II, Jean-Claude Bouvier \& Claude Martel, Paris, CNRS.

BARRAU Jacques, 1983, «À propos du concept d'ethnosciences », dans Les savoirs naturalistes populaires (actes du séminaire de Sommières, 12 et 13 décembre 1983), Paris, Éditions de la MSH, p. 5-12. Disponible sur $<$ https://books.openedition.org/editionsmsh/3689?lang=fr >.

BRETON Catherine, 2006, Reconstruction de l'histoire de l'olivier (Olea europaea subsp. europaea) et de son processus de domestication en région méditerranéenne, thèse de doctorat, Biologie des populations et Écologie, Université Paul Cézanne, Aix-en-Provence.

BoIsSier De Sauvages Pierre Augustin (abbé de), 1820 [1756], Dictionnaire languedocien-françois, version augmentée, Alais, J. Martin.

ConTINI Michel, 1986, « Les désignations du plantain dans les langues romanes », Géolinguistique, $\mathrm{n}^{\circ} 2$, p. 67-88.

COUPIER Jules, 1995, Dictionnaire français-provençal, Collectif Prouvenço.

COUTURE (abbé), 1783, Mémoire complet sur la culture de l'olivier, Aix-en-Provence, Jean-Balthazar Mouret.

COUTURE (abbé), 1786, Traité de l'Olivier, Aix-en-Provence, David.

GARCIN Étienne, 1841, Dictionnaire provençal-français, Draguignan, Imprimerie Fabre.

HONNORAT Simon Jude, 1991 [1845], Dictionnaire provençal-français, Raphèle-lès-Arles, CPM, Marcel Petit.

LE DÛ Jean, Le BerRe Yves, BRUN-Trigaud Guylaine, 2005, Lectures de l'ALF de Gilliéron et Edmont. Du temps dans l'espace, essai d'interprétation des cartes de l'Atlas linguistique de la France de Jules Gilliéron et Edmond Edmont, CTHS. 
LÉVY Émil, 1973 [1909], Petit Dictionnaire provençal-français, Heidelberg, Carl-Winter Universitätsverlag.

MISTRAL Frédéric, 1979 [1879-1886], Lou Tresor dóu Felibrige, Aix-en-Provence, Edisud.

Mouly Enric, 1977, Complibat, Rodez, Lo Grelh Roergàs.

Moutier Nathalie, PinATel Christian, MARTRe André, Roger Jean-Paul et al., 2011, Identification et caractérisation des variétés d'olivier cultivées en France, tomes I et II, Turriers, Naturalia publications.

RAYNOUARD François-Juste-Marie, 1996 [1844], Lexique roman, Nîmes, Lacour / Rediviva.

ROUQUETTE Max, 2020, Lexique occitan-français, en ligne : <http://www.max-rouquette.org/ fichiers/Lexic_MaxRoqueta_Edicion_2020.pdf>.

RUBY Joseph, 1918, Recherches morphologiques et biologiques sur l'olivier et sur ses variétés cultivées en France, Paris, Masson.

Site de l'Afidol pour les bassins de production des olives : <https://afidol.org/oleiculteur/ plantation-varietes-par-bassin-de-production/>.

TOURNEFORT Joseph PITTON de, 1700, Institutiones rei herbariae (vol. 1, p. 599), Paris.

UBAUD Josiane, 2011, Diccionari ortografic, gramatical e morfologic de l'Occitan (109 000 entrées, 1200 pages), Canet-en-Roussillon, Éditions Trabucaire.

UBAUD Josiane, 2016, «Bien écrire les noms des olives et des oliviers. Essai de nomenclature raisonnée ", dans Annales de la SHHNH (Société d'horticulture et d'histoire naturelle de l'Hérault), p. 68-116.

UBAUD Josiane, 2017, Notes éparses sur les dictionnaires occitans contemporains (languedociens et provençaux), <http://www.josiane-ubaud.com/Notes\%20sur\%20les\%20dictionnaires.pdf>.

VAYSSIER Aimé, 1879, Dictionnaire patois-français du département de l'Aveyron, Rodez, Imprimerie de Ve E. Carrère.

\section{RÉSUMÉS}

Comme lexicographe et ethnobotaniste, nous travaillons depuis des décennies à récolter les noms occitans des plantes (méditerranéennes de préférence) soit dans les lexiques locaux, les dictionnaires généraux et les écrits d'auteurs, soit sur le terrain auprès d'informateurs occitanophones, puisque nous maîtrisons deux dialectes de l'occitan, le provençal et le languedocien. Les atlas linguistiques sont aussi une source, mais à prendre avec beaucoup de précaution et de sens critique. Si la variabilité lexicale est immense pour les " petites plantes » (cela peut varier d'un canton à l'autre) et peut constituer un problème pour l'enseignement, il y a plus souvent quasi-unanimité pour les noms d'arbres, dont les noms sont issus de racines gréco-latines et se sont bien sédimentés. Les plantes plus petites obéissent à la loi des noms motivés et montrent alors un imaginaire riche. Dans l'analyse de cet important corpus lexical ayant trait aux plantes, nous nous heurtons à divers problèmes (instabilité des sources, compilations erronées, homonymies, incompétences en botanique, traductions incorrectes), que nous allons un peu détailler à partir de quelques exemples révélateurs.

As a lexicographer and ethnobotanist, we have been working for decades to collect the Occitan names of plants (preferably Mediterranean) either in local lexicons, general dictionaries and authors' writings, or in the field with Occitanophone informants, since we master two dialects of 
Occitan, Provençal and Languedocian. Linguistic atlases are also a source, but should be taken with great caution and critical sense. Although the lexical variability is immense for "small plants" (this can vary from one canton to another) and can be a problem for teaching, there is more often almost unanimity for the names of trees, whose names come from Greek roots-Latin and have settled well. Smaller plants obey the law of motivated names and then show a rich imagination. In the analysis of this important lexical corpus relating to plants, we encounter various problems (instability of the sources, erroneous compilations, homonymies, incompetence in botany, incorrect translations), which we will go into a little more detail on from a few revealing examples.

INDEX

Mots-clés : phytonymie occitane, dialectologie, dictionnaires occitans, atlas linguistiques occitans

Keywords : plant name Occitane, dialectology, Occitans dictionaries, Occitan linguistic atlases

\section{AUTEUR}

JOSIANE UBAUD

Lexicographe et ethnobotaniste en domaine occitan

jb.ubaud@wanadoo.fr 